\title{
MIDDLE PALEOLITHIC SKILL LEVEL AND THE INDIVIDUAL KNAPPER: AN EXPERIMENT
}

\author{
Metin I. Eren, Bruce A. Bradley, and C. Garth Sampson
}

\begin{abstract}
It has been proposed that Paleolithic studies should abandon their focus on groups and turn instead to the individual. If individuals are to emerge from the lithics-dominated Middle Paleolithic record, the best chance of success is to identify the products of learner knappers from those of their mentors. To do so we need a framework of knapping standards by which to measure Middle Paleolithic skill level. Selected measurements on a sequence of 100 subcircular Levallois tortoise core reductions by a knapper of intermediate skill were compared with 25 reductions by his highly experienced instructor. Four measures emerge as potential markers of skill level: total stone consumption during initial core preparation, consumption from the upper and lower core surface, symmetry of the first detached Levallois flake, and failure rate of that detachment by overshooting the core's rim. These markers allow us to discriminate between the work of a modern learner and his mentor, but $>30$ percent were misclassified. The learning trajectory is more complex than the mere honing of skills through practice and is punctuated by increasing numbers of mentor-like reductions. It follows that skill-level measures on their own are imperfect discriminators. Personal markers other than those of skill level must be found by which to seek individuals in the Middle Paleolithic record.
\end{abstract}

Se ha propuesto que los estudios del Paleolítico deberían centrarse en el individuo y no en el grupo social. Una manera de conseguir que el individuo surja del registro del paleolítico medio, que es predominantemente lítico, es a través de la diferenciación entre productos de talla lítica del aprendiz y del maestro. Para ello, es necesario construir un marco referencial de estándares de talla que mida el nivel de destreza requerido para talla durante el paleolítico medio. En este trabajo se han realizado las medidas correspondientes en una secuencia de 100 reducciones de núcleo Levallois de tortuga subcircular llevadas a cabo por un individuo con un nivel intermedio de experiencia. Estas medidas fueron comparadas con 25 reducciones realizadas por el instructor de dicho individuo, quien contaba con un alto nivel de experiencia. Como resultado, se obtuvieron cuatro medidas como marcadores del nivel de experiencia: el consumo total de la piedra durante la preparación inicial del núcleo, el consumo de la superficie superior e inferior del núcleo, la simetría de la primera lasca levallois, y la tasa de error de dicha extracción al sobrepasar el borde del núcleo. Estos marcadores nos permiten discriminar entre el trabajo de un principiante y su maestro en la actualidad; sin embargo, $>30 \%$ quedan fuera de esta clasificación. La trayectoria de aprendizaje comporta más complejidad que la mera acumulación de destreza a partir de la práctica, manifestándose a través de un aumento en el número de extracciones de experto. Se deduce que las medidas del nivel de destreza por sí solas son discriminantes imperfectos para identificar al individuo. Para llegar a reconocer al individuo en el registro del paleolítico medio se deben reconocer marcadores personales adicionales aparte del nivel de destreza.

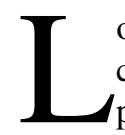

ower and Middle Paleolithic scholars are currently debating the merits of a proposed paradigm shift away from collective behavior (social groups) toward a new focus on the individual (Dobres 2000; Gamble and Porr 2005 and references therein; Hopkinson and White 2005; Machin 2009). This debate has ramifications for all of us, including any readers of American Antiquity who are involved in hunter-gatherer lithic analysis.
Proponents of the shift insist that the individual should become the proper focus of Paleolithic research. Individuals, they argue, make all the decisions and choices, perform all the actions that might leave behind physical traces, and are (besides much else) the vehicle of choice for explaining the material record, what Gamble and Porr (2005) call the "centre of causality." Seen in this light, "racloirs" (side scrapers) were not made by "the Mousterian"

Metin I. Eren — Department of Anthropology, Southern Methodist University, Campus P.O. Box 750336, Dallas, TX 75275-0336 (meren@smu.edu)

Bruce A. Bradley Department of Archaeology, University of Exeter, Exeter (b.a.bradley@exeter.ac.uk)

C. Garth Sampson $\square$ Department of Anthropology, Texas State University, San Marcos, TX 78666 (cs48@txstate.edu)

American Antiquity 76(2), 2011, pp. 229-251

Copyright $\odot 2011$ by the Society for American Archaeology 
but by individual Neanderthals, who caused them to vary in design. Our mistake has been to suppose that "the Mousterian" has somehow deposited a set of designs in the heads of their makers; hence we seek to understand different sets of Mousterian rules-Ferrassie rules, Quina rules, and so forth. This has proved a fruitless endeavor in large part because we think in terms of Mousterian rather than individuals. Similar injunctions may be leveled at the other warhorses of Middle Paleolithic debate such as the functions of specific tool types, the constraints of raw materials on the fashioning of tools, and (lately) the role of sexual selection in the makeup of tool assemblages. Each of these approaches is concerned with the discovery of rules for groups, and each has proved to be a dead-end avenue of inquiry, or so the argument runs.

A shift of focus to the Middle Paleolithic individual must perforce deal with the same limited range of flaked lithics that dominate previous studies. This does not imply that items made of organic materials are unimportant, just that they are too rare to be much use here. The role of the individual agent, if it is to be discerned at all, will have to be teased out from the same mass of lithics as before-it will have to be expressed in terms of stone artifacts.

If individual agency can be recognized, there is no question that Middle Paleolithic studies would benefit. It will improve our understanding of the ways that typological variability comes about not only at the levels of the component or the site but also at the regional level. It promises also to greatly refine our understanding of the processes underlying widespread technological changes through time (Bamforth and Hicks 2008:133). The hope is that many more nonutilitarian questions about Middle Paleolithic life may be addressed this way: the individual's relationship to the group, to the local environment, to the ambient material culture (those inescapable rules again), and to the immediate needs of the moment.

While we suppose that all or most of this is anathema to those of our colleagues who see themselves as anthropologists of the past, we find ourselves sympathetic to the cause mainly out of frustration with the nature of current inquiry into Middle Paleolithic behavior. Despite our frustration, we stress that the old paradigm should not be abandoned. In our view, studying both the group and the individual in tandem is the most fruitful way forward. Agency can be collective, for example, where it exerts a culturally selective force on stone tool form over several generations (e.g., Lyman et al. 2008). Likewise examining the individual helps us study group behavior: questions arising from activity areas (site use) could be quickly resolved if only we could track individuals across the site by their lithic "signatures." Intersite mobility would no longer be entirely tied to raw material procurement. If individual lithic signatures are strong enough, it might even be possible to tease apart assemblages from palimpsests (e.g., Vaquero 2008) by separating out the work of specific individuals.

However, we are pragmatists, less interested in building further arguments to bolster the case for studying the individual, less interested still in offering critiques of existing arguments, but really, very interested to know if we can actually do it - tease an individual out of a lithic assemblage. If not, then we cannot begin to explore the combination of factors that influenced each individual's agency, identity, or choices - all stated goals of the proposed new paradigm. If not, then the lithic assemblage reverts to its previous status: the product of an unknown number of anonymous individuals-a group.

Promoters of the individual all understand that we must find tangible, plausible individuals among the flakes-individuals to whom we can give names, individuals whom we can track from site to site. Machin, for one, calls for "a test against the record" (2009:51) but concedes that the archaeological record is beset with time-averaged palimpsests and far too few occurrences in pristine contexts with unmixed and refitted lithics that reflect the one-off droppings of individual knappers (e.g., Schlanger 1996; Van Peer 1992).

We agree that such occurrences will be vital to the whole endeavor, but not yet. The archaeological record is not the best place to start the search, especially as we have only generalities about what distinguishes one knapper from another in the lithic record. We need first to determine, under strictly controlled conditions, that the replicated Middle Paleolithic handiwork of one modern knapper can indeed be distinguished from that of another; and that is what we set out to do.

So how are we to begin identifying individuals in the Middle Paleolithic record? Armed with lit- 
tle else but stone artifacts, we need to find or assume the intentions of a knapper and understand how well they were carried out. It is axiomatic that each individual is different from all others not only in motor habits and/or motor performances (skill) but also in aesthetic choices and preferences (style [Hill and Gunn 1977:2]). Rather than examine these two concepts in tandem, we have attempted to isolate them, focusing here only on the former: skill. By examining them in isolation first, we hope in the future to have a much more thorough understanding of how they can be combined to identify individuals by their artifacts. Though we acknowledge that the line separating the two is often a blurry one, we make the following distinction: style is largely subconscious and aesthetic (we may not know why we like a particular artifact trait), while skill is cognizant and technical (we know how capable we are of achieving the ideal artifact trait [Close 1989; Costin and Hagstrum 1995; Hill and Gunn 1977; Rick 1996; Weedman 2002; Wiessner 1983]). At the most basic level it seems reasonable to question, as Bamforth and Finley (2008:6) do, whether a knapper will express a personal style until particular skills are mastered. If this is the case, we cannot hope to recognize a personal style in the lithic record until we have ways to judge how fully the basic skills have been acquired (Porr 2005:77). We should expect the end products of a beginner/novice to look rather different from those of a knapper with decades of experience in fashioning the same objects. Yet it is important to realize that unconscious and aesthetic personal styles may begin to develop during developmental and learning stages, though they may not be fully shaped until skill mastery (Bamforth and Finley 2008:6).

Most agree that skill is going to be a central factor, among many, if we are to identify the individual through lithic analysis (Bamforth and Finlay 2008; Finlay 2008; Hill and Gunn 1977; Hopkinson and White 2005; Machin 2009; Olausson 2008; Petraglia et al. 2005; Plog 1977; Redman 1977; Sinclair and McNabb 2005; Stahl 2008; Weedman 2002; Whittaker 1987, 1994). When producing artifacts, each individual may differ from all others in three distinct ways that influence his or her skill (Read 2006:165): (1) the amount of knowledge about the task that each possesses, (2) the amount of time each has for training and practice, and (3) the phenotypic ability each possesses in motor skill level. Phenotypic (in)ability requires long periods of practice and training to overcome and may never be surmounted. It may also be influenced by age, as strength increases from childhood to adulthood (Ferguson 2003; Petraglia et al. 2005).

The large subcircular Levallois tortoise core (LTC) and the faceted-platform flake detached from it are the targets we use for the comparison (Figure 1; known as preferential Levallois in the Old World literature [see Eren and Bradley 2009 and references therein]). Although countless introductory texts would have us believe that the purpose of the tortoise core is to supply a large subcircular flake that mimics the outline of the parent core's surface, we cannot yet discern the true intentions of LTC knappers in the Middle Paleolithic. This is demonstrated by the array of current proposals for the role of LTC reduction. One is that LTC reduction produces flakes of predetermined size and shape (Bordes 1961; Sellet 1995). Another is that it mitigates increasing convexity and central mass of "single-surface cores" (Sandgathe 2004:153), while its products possess inherent advantages for specific conditions or actions (Sandgathe 2005). Yet another proposal is that it minimizes waste while maximizing production of certain traits (Brantingham and Kuhn 2001). Others hold that it is simply a technological/cultural variant of discoidal or, more generally, bifacial technologies (Ohnuma 1995). Perhaps the most extreme position is that it does not produce anything predetermined or special and that Levallois flakes are random, inevitable occurrences (Noble and Davidson 1996).

If the goal of the LTC reduction sequence remains this uncertain, can we really recognize skill level at all? Ferguson thinks not: "The relationship between artifact variability and skill is complex and may be difficult to apply to archaeological lithic assemblages without knowing more about the goals of production and the differences in raw material access" (2008:65). We do not pretend to know the original goals of production but set out to demonstrate that skill can be measured nonetheless. For purposes of the experiment we adopted goals of our own: to produce a large, symmetrical Levallois flake that covers as much of the prepared core surface as possible without consuming too much raw material. That our end products replicate some of those in the archaeological record suggests we have come close to guessing 

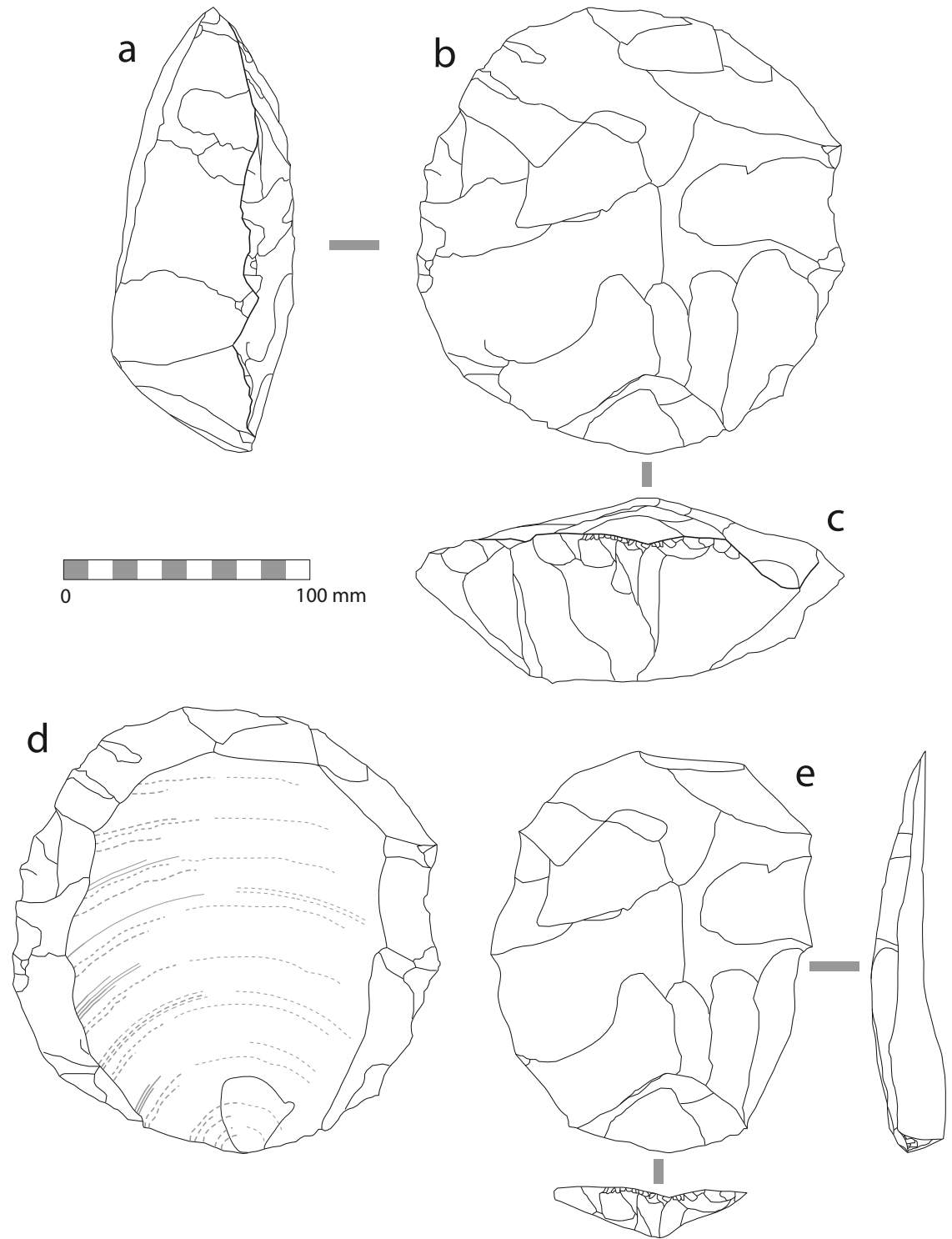

Figure 1. Levallois Tortoise Core (LTC). (a) Left side of the unstruck core, (b) the ventral surface, (c) the prepared striking platform, (d) ventral surface of the struck core, (e) the initial Preferential Levallois Flake (PLF).

at least the goals of production that concern lithic technology.

Nor do we pretend to have replicated a Middle Paleolithic learning environment or experience. A knapping experiment in a modern lithics laboratory, well supplied with quality stone, and narrowly focused on one reduction sequence cannot presume to replicate the lifetime experience of Middle Paleolithic knappers. When we strike stone and produce similar results to those of prehistoric knappers, we cannot presume to have directly copied their actions. However, stone breaks the same way no matter who strikes it, and this encourages us in the belief that knappers past and present make analogous mistakes. And the stone dictates how those mistakes are to be remedied. That is the limit to which we assert we are replicating Middle Paleolithic knapping behavior. Our focus remains strictly on the lithic technology, not on the needs that surely lay behind the prehistoric knapping. 


\section{Knapping Skill Level}

Mastery of a particular knapping skill means that the learner is producing a specific knapping product in a regular fashion with a minimum of wasteful mistakes. How quickly and consistently the learner reaches that vaguely defined threshold depends on the time invested by both learner and teacher (Porr 2005:77) and on the learner's age (Bamforth and Finlay 2008:11), mood (Finlay 2008:69), and inherent flintknapping talents (Olausson 2008:39). The abundance and quality of flakeable stone available for practice will also influence the learning outcome (Porr 2005:77). The mix of all these factors will vary from one learner to the next, so that each learner ends up with a specific skill level somewhere within a poorly defined threshold that the teacher deems adequate.

For the Middle Paleolithic lithic analyst, knapping skill haunts (and renders dubious) all those overtidy typological divisions we like to impose on any given Paleolithic assemblage. We simply do not know what mix of knapping skill levels generated the assemblage or the extent to which they shaped its overall character (Bamforth and Finlay 2008:9; Shea 2006:214). This is reason enough to study knapping skill, but there are many others (see Milne 2005; Whittaker 1987). We agree that the longterm accumulation of skills by humans is the very foundation of "technological complexity and achievement, and much of what passes for intellectual growth" (Bleed 2008:155). Yet those same variations are also a major part of identifying individual knappers and perhaps still grander targets such as the socioeconomic status of the knapper (Roux et al. 1995:64), social groupings (Apel 2008), or even age groups (Hogberg 2008:117) all to be read from the lithic record if only we can determine knapping skill level.

According to Roux et al. (1995:66), skill refers to the capacity to reach a goal by using available resources. To acquire a skill we learn how to act in order to solve a problem, rather than acquiring some rigid motor formula (Stout 2002:694). So skill denotes actions that can be learned and improved with practice (Olausson 2008:30). This leads to "well-organized behavior (that is acquired through practice) and performed with economy and effort" (Proctor and Dutta 1995:18, cited in Bamforth and Finlay 2008:1). Each of these statements refers in its own way to some aspect of the proficiency with which activities are executed (Bleed 2008:156). In last resort, any activity should be considered a skill if it has an established goal consciously recognized by the agent performing that activity and by the agent's peers. A reasonable definition of an individual's skill level is the measure of an activity's result against the activity's intended outcome. It follows that if we want to evaluate a stone knapper's proficiency, it is necessary to have a standard (datum) against which to judge performance (Stout 2002:705).

How is this standard to be established? There are dozens of recognized reduction sequences in the Paleolithic record (Oldowan, discoid-Levallois, prismatic blade, to name but a few), and each will need its own datum for measuring aptitude, although a few traits may be common to all. Overshots, step/hinge failures, misstrikes, and platform failures are widely perceived to be common traits of beginners, no matter what reduction is being taught. The small pool of studies of knapping skill level (e.g., Andrews 2003; Grimm 2000; Roux et al. 1995; Shelley 1990) turn out to be not much use here because the reductions observed are not really analogues for the Middle Paleolithic ones we wish to measure. The one exception is Stout's study of adze making by the Langda of Irian Jaya (Indonesia), which makes a major contribution to the whole field of knapping instruction by establishing, for the first time, a "clear pattern of differences between established and apprentice craftsmen" (2002:705) and further points to end product symmetry as the most prominent way to distinguish learners from experienced practitioners.

To serve as markers of skill level, both symmetry and several other aspects of the reduction sequence will require a datum, a skill-level standard, and these are not to be found in the scant ethnoarchaeological record of stone knapping. They can only be obtained through replication. An analogue scale of knapping ability must be constructed from samples of work by knappers of different skill levels, from those of long experience to those of intermediate ability to complete novices. This approach was pioneered by Winton (2005), who compared archaeological samples of Acheulean hand axes to experimental replicas knapped by individuals of differing skill levels. While her experiment nicely demonstrates Newcomer's (1971) and 
Schick's (1994) hypothesized steps toward the mastery of hand ax production, she could not convincingly separate the experienced knapper from the novices for want of rigorous controls of the latter samples. Had they all been given the same shape to replicate as that given to the expert, a valid comparative sample would have emerged. Nonetheless, Winton's (2005) overall concept is sound: if skill levels become recognizable (through product measurements) among modern knappers, those results could act as a middle-range bridge to similar products in Paleolithic contexts.

Stahl's (2008) recent study of skill and style regarding small bifacial projectile points exemplifies this approach. By giving the 56 flintknappers in her experiment the same lithic form to replicate, she was able to find statistical differences between novices and experts. Unfortunately, we cannot simply impose her examined traits onto the study of LTC technology for an obvious reason: LTC technology does not possess basal notches, abrading episodes, or other features inherent only to the production of small bifacial projectiles. Yet such an approach has promise and should be developed further using traits appropriate to the technology in question here.

A major hazard will be the individual's lifetime learning trajectory. As he or she gets better at it, the individual's skill level can reasonably be expected to rise. There will be changes in motor skills due to advancing age, perhaps punctuated by illnesses survived. In addition, there will be many external factors causing skill level to fluctuate as the individual moves about on the landscape during the seasonal round-changes in available rock types, changes in time available for knapping, and so on (e.g., Apel 2008; Bamforth and Finlay 2008; Ferguson 2008). It may be likely that the Paleolithic knapper's personal style also changed during his or her lifetime.

As many specialists now realize, what is needed first is a set of quantified studies that document in detail "knapping skills over a long period of time [that] ... consider variability in performance" in a single knapper as he or she grows in proficiency (Finlay 2008:87; see also Finlay 1997:210; Olausson 2008:34). It is from such a measured output that the most suitable markers of skill level are likely to emerge for any particular prehistoric reduction sequence.

\section{Research Design}

We set out to develop a system of measurements that would place individual Levallois tortoise core reductions along a graded trajectory of improvements. The underpinning assumption was that learning Levallois entails the steady honing of skills (Milne 2005:337). Our system was to be designed so that it would group cores (and their products) made at, say, two weeks, a month, three months, or some other intervals. That way, we hoped to classify LTCs and their first preferential Levallois flakes (PLFs) by learning stages, e.g., early learner, intermediate, late learner, or some such. This was to be accomplished by artifact measurements alone, without any reference to their archaeological context. We hoped it could be applied to Middle Paleolithic assemblages in less than pristine contexts, perhaps even to surface sites. For rare, refittable assemblages it would serve in tandem with spatial analyses to help verify the presence of apprentice knappers.

The difficult "tortoise core" reduction pathway (Figure 1) is just one of the family of Levallois reductions known to Middle Paleolithic knappers (e.g., Chazan 1997; Dibble and Bar-Yosef 1995). Several factors guided our choice. Not only is it nearly ubiquitous in the Middle Paleolithic record of Europe, Southeast Asia, and North Africa, and thus of the widest possible relevance, it is also technically very demanding. There is a fair chance, then, that a run of reductions would capture in some fashion the growing aptitude over time of a learner.

To this end we acquired supplies of suitable stone (Milne 2005:335) and set about measuring the progress of an intermediate knapper (Eren) toward mastery of tortoise core reduction, and then we compared his results with those of his mentor (Bradley [see 1977]), who began to study tortoise core replication over 30 years ago and who still teaches the method today. Over the course of three months Eren knapped 100 LTCs and recorded specific attributes that promised to reflect changes in his overall skill level.

LTC technology calls for not only a sound grasp of lithic reduction (connaissance) but also a high manual skill level (savoir faire [cf. Sandgathe 2005:3]). Difficulty notwithstanding, LTC technology revolves around a quite simple goal, the production of what Bradley (1977) and Sellet (1995:7) 
call the single preferential Levallois flake. Much connaissance is invested in visualizing and building the required convexity on the core surface for removal of a perfect PLF, to be described below, while savoir faire is required not only for the accurate preparing of facetted platforms but also for confidant detachment of the PLF itself.

The successful detachment of a large, symmetrical Levallois flake from the prepared upper surface of a tortoise core is too complex for a complete beginner/novice knapper. It requires prior experience and expert instruction. For a first knapping lesson to begin with the LTC reduction would be akin to the first piano lesson starting out with a sheet of Liszt. As it happened, Eren had already acquired some connaissance and savoir faire over four years of largely self-taught knapping. Experience grew by personal trial and error during which he mastered bifacial hand ax production, discoidal flake production, and simple blade production from unshaped cores with plain platforms. But without hands-on instruction, his attempts at LTC reduction had met with no success.

During the four-five weeks before the experiment began there were three one-on-one sessions with Bradley. At the first session, Eren watched and listened while Bradley demonstrated; at the second, Eren knapped while Bradley told him which flake to detach next; in the third session, Eren told Bradley which flake he planned to detach next, and the choice was discussed before striking. At all sessions the motions of arms/hands were discussed and practiced. Thus, Eren began the experiment with just four-five weeks' background in LTC production. The goal here was to coach him to the threshold where he could produce an LTC but had yet to perfect his method. It was agreed that Eren would consult Bradley at any stage during the experiment, so that his improvements would be guided, not solo.

At no time was the intent to mimic the learning experience of Middle Paleolithic knappers; quite the contrary. Before and throughout the experiment Eren also received instruction on several other reduction technologies, which probably influenced his acquisition of LTC skills in countless but unfathomable ways, obviously not shared by learners in Middle Paleolithic times.

Following Bradley (1977:22), preferential Levallois flakes are created in two stages, the latter of which is divided into three steps: Stage I produces the preliminary bifacial margin, continuous around the circumference of the nodule (Figure 1a). Stage II includes all of the remaining flake removals, divided into three steps: (1) core surface (ventral) shaping and margin adjustment (Figure 1a-b), (2) platform preparation (Figure 1c), and (3) standardized PLF production (Figure 1d-e).

At the start of each LTC reduction (Stages I, II[1], II[2]) Eren was instructed to bring the stone blank to its correct tortoise core shape with as few blows as possible, thereby creating the largest, most symmetrical core that the blank shape would allow while using up the least stone (Figure 1a-c). For his final blow on the prepared platform (Stage II[3]) he was to strike off the PLF from the core's gently curved ventral surface (Figure 1d-e). In every case the PLF was to be as large and symmetrical as the ventral surface would permit, but without plunging (overshot) edges (Figure 2g). To maintain the tightest possible control, reduction was halted after his first PLF removal (Figure 2a-f).

Middle Paleolithic LTCs were usually recycled by re-preparing the ventral surface and its perimeter to detach a second PLF and so on until the core became exhausted, i.e., the last PLF was too small for the knapper's needs. Although unexhausted cores like ours are uncommon in the prehistoric record, they are more frequent where large nodular or block-shaped blanks were abundant. The classic example is Baker's Hole in the Thames Valley, England (Wenban-Smith 1996). We elected to halt reduction after the first removal to avoid cluttering our database with too wide a range of PLF sizes that might mask the attributes we sought.

Somewhere in this 100-core experimental sample we hoped to isolate a few measurable attributes that would serve as legitimate markers of Eren's rising skill level. If we could isolate these, we intended to compare his marker attributes with their equivalents from a smaller sample made by Bradley after he had been making LTCs intermittently for about five years, having been initially taught by Francois Bordes in 1970. Twenty fully reduced Levallois cores provided some of the metrics we would need (Bradley 1977). For a recent comparison, Bradley made five new LTCs (in May 2009) on large flakes of the same stone used by Eren. These were made after about 35 years' experience in LTC production. 


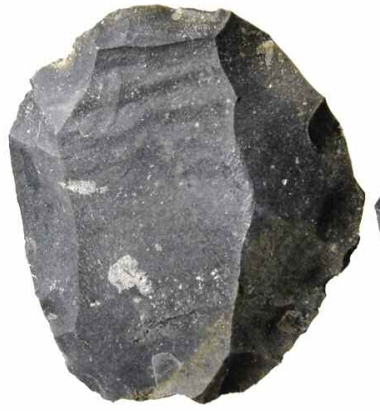

a

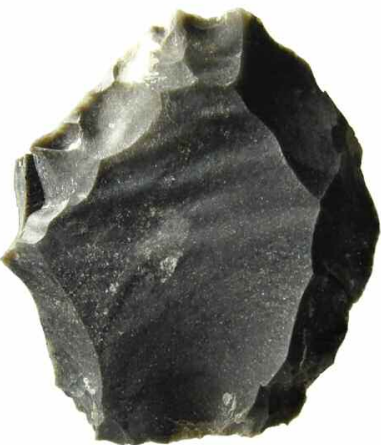

e

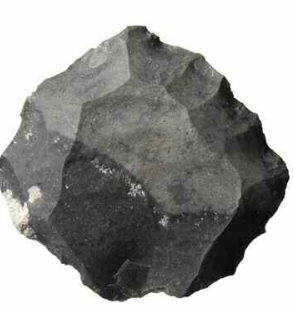

b

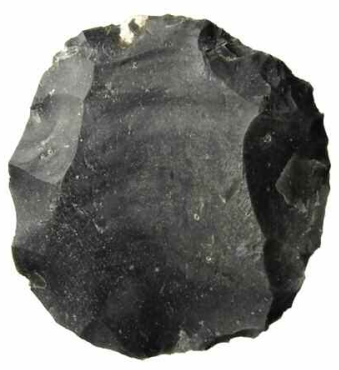

C

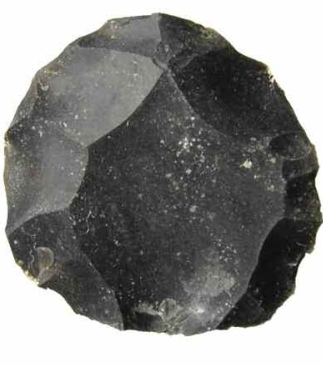

d

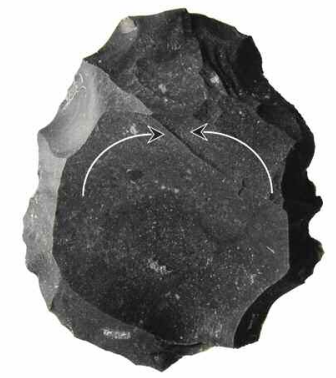

f

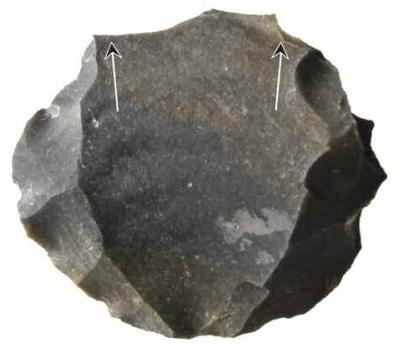

g

Figure 2. Levallois Tortoise Cores (LTC's) from the 100-core replication sequence: (a) specimen \#23; (b) specimen \#25; (c) specimen \#36; (d) specimen \#48; (e) specimen \#74; (f) specimen \#100, arrows denote a high-symmetry preferential Levallois flake (PLF) detachment terminating inside the rim of the core; (g) specimen \#24 failed (overshot) detachment; arrows show where the PLF plunged over the LTC rim.

We decided before the experiment began that our first choice of potential skill-level markers would be step/hinge fractures, widely believed to be a prominent flaw of all novice flintknappers (Shelley 1990). After the first 10 cores were searched, it became clear that Eren was too experienced for these to occur in any significant number; in fact he was on occasion deliberately creating step fractures to serve various expedient purposes. Because their presence on a core marked as many (if not more) knapping successes than failures, recording of step fractures was abandoned.

We were drawn next to the preferential Levallois flake. Our first notion was that the facetted striking platform with its multiple scar beds (Figure $1 \mathrm{c}, \mathrm{e}$ ) would be a likely candidate for revealing skill level, but none of us could discern any clearly contrasting patterning whatever between the two sets of flakes. So we decided to concentrate on simpler attributes of the PLF.
Bradley (1977) posits that striking the PLF, Stage II(3) of his scheme, was by far the most demanding. Three separate goals must be attained in one culminating blow: (1) the fullest possible removal of the ventral surface, (2) without overshooting the core rim but (3) following just inside the core rim to yield a large symmetrical, subcircular flake (Figure 1d). Eren soon confirmed that bringing off these three tasks with one strike was the most difficult task of all, in that both knowledge and practice must be carefully combined (cf. Apel 2008). Here, we reasoned, were the most promising places to find attributes that could discriminate between the skill levels of master and apprentice.

Our choices in no way presume to mimic the intentions of Middle Paleolithic knappers. We doubt (but cannot know) whether they thought that larger, more symmetric PLFs were better than smaller crooked ones or that overshot PLFs were 
completely useless. Our experiment is concerned only with skill level, not with the thorny issues of PLF utility. What we do know is that "ideal" LTCs (all three goals met; see Figure 1d) are to be found, usually in low frequencies, at Middle Paleolithic sites over whole subcontinents, so it is reasonable to assume that prehistoric knappers sometimes aspired to a comparable perfection. Why they did so remains unknown (see above). Overshot PLFs are also widespread and are in such low frequencies as to raise legitimate doubts whether they were deliberately produced. An overshot ruins the core's working surface, which must be completely reworked with much waste of good stone, and is therefore a production failure reflecting a lower skill level.

Next, to escape our obsessive concern with the PLF, we pondered what other attributes of LTC production might be sensitive to the learner's trajectory. It struck us that the ubiquitous core recycling by Middle Paleolithic knappers must reflect a near-universal concern with conserving stone during reduction. From the outset they would want to set up the LTC blank with the fewest possible blows, thus consuming the least possible stone. With this in mind, Eren worked toward finishing the LTC blank with the fewest possible strikes and the least possible loss.

Early in the experimental run it appeared that much stone was being used up while rounding out the core's perimeter, in particular when striking flakes off the core's domed underside, here called the dorsal surface (also known as the lower face or the preparatory surface). Eren needed to improve his ability to locate the ventral surface (also known as the upper face or the striking surface) in such a way that this domed underside would require less trimming. If he could do this, he would reduce his overall stone consumption and with time would also produce more ventral flakes and fewer dorsal ones. As his planning judgment improved, we ventured that the ratio of total ventral flakes' mass divided by total dorsal flakes' mass would increase.

\section{Methods}

\section{PLF Area as a Percent of Core Ventral Surface}

To measure how close Eren had come to removing the largest PLF that the ventral core surface would allow, he settled on this simple procedure: take the surface area of the PLF $\left(\mathrm{mm}^{2}\right)$ and compute it as a percentage of the prepared core's ventral surface area $\left(\mathrm{mm}^{2}\right)$. For high accuracy we used a computer-assisted method similar to that developed by Eren et al. (2008; see also http://www.thinkcomputer.com/research), but this one used a special plug-in for Adobe Illustrator CS2 called "path area filter" (created by Telegraphics and downloaded from http://www.telegraphics.com.au/sw/\#filterfoundry). This percentage serves well for ranking how closely he came to removing the whole ventral surface. In cases where the detaching blow was too hard, an overshot termination (Figure $2 \mathrm{~g}$ ) was first ranked as outright production failure (see above) and received a surface area score of zero. An alternate ranking with the overshots removed from the sample is also presented.

\section{PLF Symmetry (Eccentricity)}

This is a measure of how well the edge of the flake follows the outline of the LTCs' subcircular ventral surface rim. Here symmetry is treated as a technical attribute sensitive to skill level, not as an aesthetic one. Although symmetrical PLFs occur in low frequencies in most places where Levallois is to be found, we cannot presume to know whether they were desired end products.

The outline of the PLF is converted to a 36-point polygon with 18 axes centered near the midpoint of the flake's axis of strike (Figure 3a). The polygon is compared with an ideal symmetrical oblate (Figure 3b), in which each axis is the same length as its equivalent in the flake's polygon. However, the oblate's axes are all bisected at one midpoint, halfway up the vertical axis. The goal of the method is to measure the direction and extent to which the flake edge diverges from its symmetrical oblate equivalent (Figure 3c).

The procedure is conducted in Adobe Illustrator; there are no direct measurements and only two calculations per flake. First, a standard jig is created as shown in Figure 3d: three horizontal bars exactly $100 \mathrm{~mm}$ apart with a vertical passing through each. Sixteen inclined axes at $10^{\circ}$ intervals are passed through the point where the middle horizontal bisects the vertical. This is the jig's center. The jig is placed in one Illustrator layer and can be recycled at the end of each operation.

Next, an outline of the PLF (a continuous vec- 


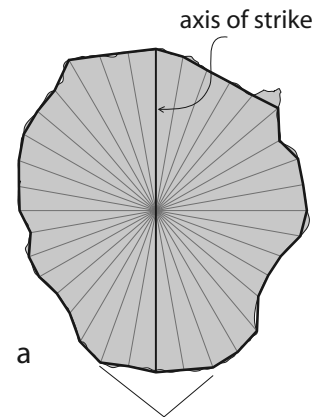

facetted platform

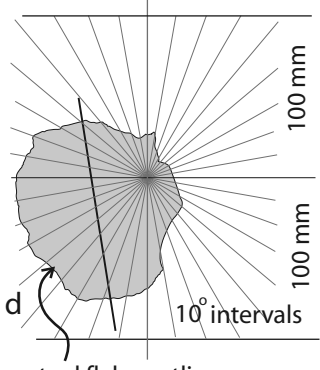

actual flake outline

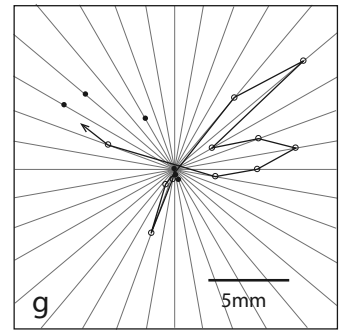

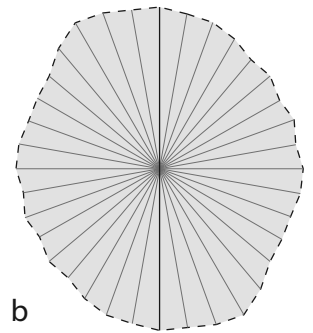
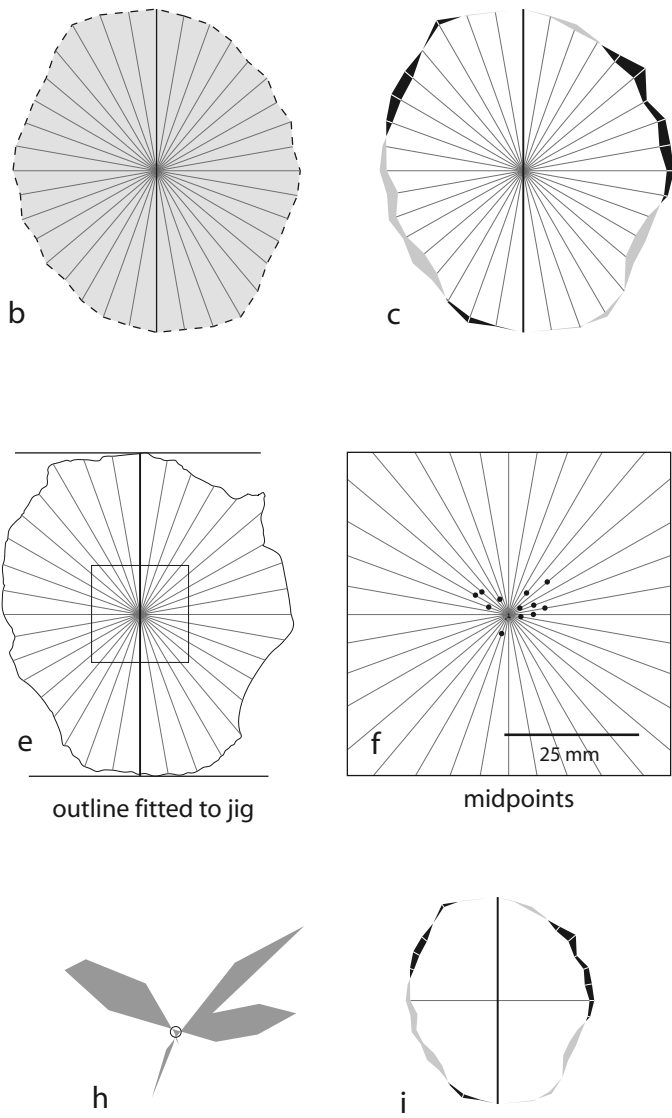

Figure 3. (a) 36-point polygon (thick line) fitted to the primary Levallois flake outline (gray) and centered on the midpoint of the flakes' axis of strike; (b) ideal symmetrical oblate of identical proportions to the flake; (c) directions and extent to which the flake departs from ideal symmetry, both within (gray) or beyond (black) the ideal oblate edge; (d) the PLF outline (gray) and strike axis are placed under a symmetrical jig with radii at 10 degree intervals; (e) the flake outline is enlarged and rotated to fit the jig, platform down and strike axis aligned with vertical. Axial maximum length of the flake is now $200 \mathrm{~mm}$. Ends of all other inclined axes are then dragged to fit the flake; (f) midpoints of all inclined axes are plotted, the 18th point (not plotted) is the midpoint of the vertical axis; (g) clockwise joining midpoints in progress (open circles) with six points (black) to go; $(\mathrm{h})$ joins completed, the figure is converted to a complex polygon reflecting the extent and direction of the flake's total eccentricity (i), see also Figure 3c.

tor line traced from the edge of a scanned image) is placed in the layer below the jig. The flake's axis of strike has been added to the outline beforehand (Figure 3d). The vector outline is then fitted to the jig with its strike axis aligned to the vertical of the jig (Figure 3e). This is done with the Percentage and Rotate tools in Illustrator. The flake's axial maximum length is now standardized to $200 \mathrm{~mm}$. Note that this is slightly longer than the strike axis itself, so that the jig's midpoint is close to but not precisely on the flake's axial midpoint. That done, the ends of all axes are dragged to the edge of the flake outline (Figure 3e) so that the jig now fits the flake.

The midpoint of each axis is located by simply clicking on the axis itself. Black circles (housed in a third layer) are dragged into position at each highlighted midpoint (Figure 3f). Since the midpoint of the vertical axis is always at the jig's center, this is not marked. All points are then carefully joined by a thin line drawn in another layer above the rest. The line begins at the (unmarked) jig center and proceeds in strict clockwise order, thus the first join is to the midpoint of the $10^{\circ}$ axis to the right of ver- 


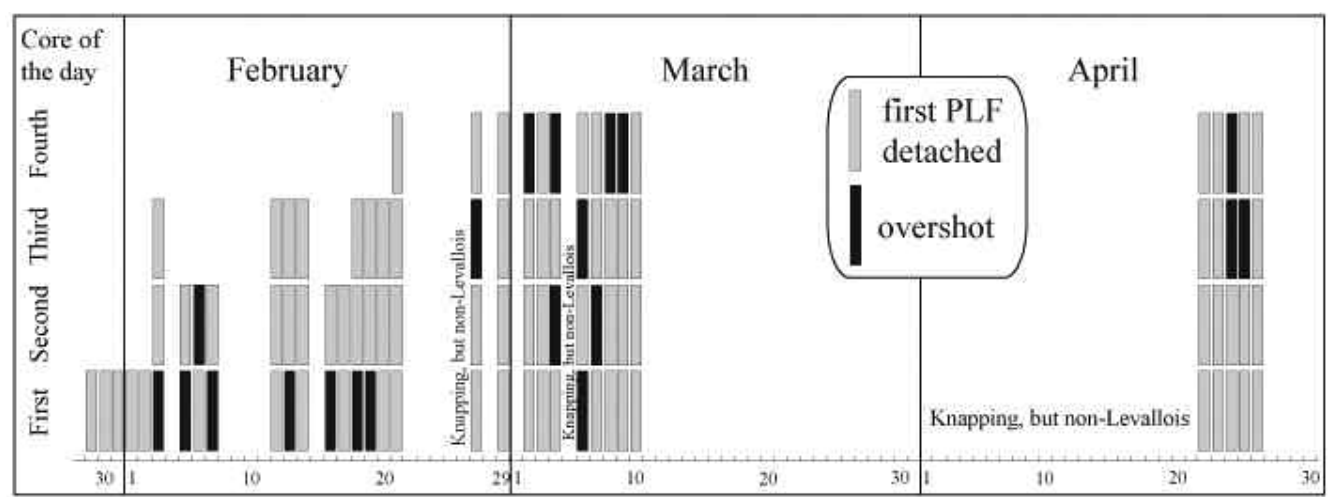

Figure 4. Schedule of Levallois Tortoise Core (LTC) production for the replication experiment. Overshots occurred throughout the experiment. The experiment took place during February, March, and April of 2008.

tical, then to the $20^{\circ}$ axis, and so on (Figure $3 \mathrm{~g}$ ) for 17 joins, finishing again at the diagram's center.

The resulting figure is converted to a complex polygon (Figure 3h). Component "petals" of this polygon exaggerate those parts of the flake's edge that flare outside the boundary of ideal symmetrysee Figure $3 i$ for comparison. The PLF used here is an example of moderately high symmetry (small overall size of polygon, see below) and flared at the distal end, as shown by the $\mathrm{Y}$ configuration of the polygon. Thus large amounts of data are compressed into a single diagram. More asymmetric (eccentric) flakes yield more widely scattered midpoints, hence larger polygons, thus the area of the polygon is a simple measure of its overall symmetry. The area of the complex polygon is measured by the same methods described above for PLF area.

\section{Debitage as a Percent of Blank Mass}

To measure how much stone Eren had detached on the way to getting the LTC ready for its first PLF detachment, he weighed the large piece that he had chosen as the blank before flaking commenced and then weighed the finished LTC just before striking the first PLF. The prepared core mass (g) was then computed as a percentage of the original, unmodified blank. The higher the percentage score, the less stone he had wasted in getting the core ready.

\section{Dorsal/Ventral Debitage Ratio}

The mass of flakes struck from the ventral surface of the LTC is divided by the mass of flakes generated to form the dorsal surface. The ratio's value increases as the dorsal shaping becomes more economical.

\section{Timetable}

The experiment took place during February, March, and April 2008 (Figure 4). Eren initially planned a single LTC reduction per day, but this did not allow learning or muscle-memory development, which require more constant knapping. Thus, his rate of LTC reductions was increased to two, then three, and then four reductions per day. Occasionally breaks from LTC knapping were taken, during which other technologies (laminar, discoidal, bifacial) were practiced and more stone was acquired. Thus the three-month timetable (Figure 4) of LTC output included tactical pauses to see if such gaps would cause any dips in what we expected would be a gradually rising skill level. The compressed time frame of this experiment was never intended to replicate the actual learning trajectory of a Middle Paleolithic apprentice, about which we can only speculate.

\section{Materials}

The only rock type used by Eren was a fine greensand silicate procured from the Cretaceous chalk cliffs of Seaton on the Devon coast, United Kingdom. This is an exceptionally homogeneous, flawfree stone with no voids or cleavage lines and is of very good flaking quality. It was not heat treated. Blanks used for core preparation were collected in six expeditions over the three months of the experiment. These were very large flakes from outcrop and/or beach boulders, produced by hard-hammer direct percussion (Table 1). The first three sets of large flakes (\#1-25, \#26-50, \#51-75) were statistically the same size, but those large flakes used for 
Table 1. Summary Metrics for the Large Flakes Used as Core Blanks.

\begin{tabular}{lcccc}
\hline & Mass $(\mathrm{g})$ & Maximum Length $(\mathrm{mm})$ & Medial Width $(\mathrm{mm})$ & Medial Thickness $(\mathrm{mm})$ \\
\hline Sample Size & 100 & 100 & 100 & 100 \\
Mean & 1717.7 & 198.07 & 144.45 & 61.35 \\
Standard Deviation & 783.3 & 31.87 & 23.10 & 16.53 \\
Median & 1560.9 & 194.69 & 142.60 & 57.52 \\
Range & 3860.5 & 154.59 & 108.87 & 74.59 \\
Minimum & 610.6 & 136.54 & 99.74 & 34.29 \\
Maximum & 4471.1 & 291.13 & 208.61 & 108.88 \\
\hline
\end{tabular}

the last 25 cores (\#76-100) were statistically smaller than the other three sets (Figure 5, Table 2). Large flake morphology was on average statistically similar for all four sets (Table 2). Bradley used flakes of this same material for the five cores produced in May 2009. The earlier set of Bradley's cores was made on flat nodules of Edwards chert (Georgetown variety, Texas).

\section{Logistics}

For the LTC shaping, direct, freehand, hard-hammer percussion was used throughout. Following recent authorities (Boeda 1995; Bradley 1977), dorsal and ventral flakes are not removed in discrete sequences.

As each flake was detached from the core it was immediately placed in a dorsal flake pile or ventral flake pile before the next detachment. A large canvas tarpaulin was placed underneath the knapping area to catch all small waste chips (e.g., from platform faceting or edge trimming), which were collected and saved after each reduction. Upon removal of the first intended PLF, core reduction ceased. All specimens are currently stored in the

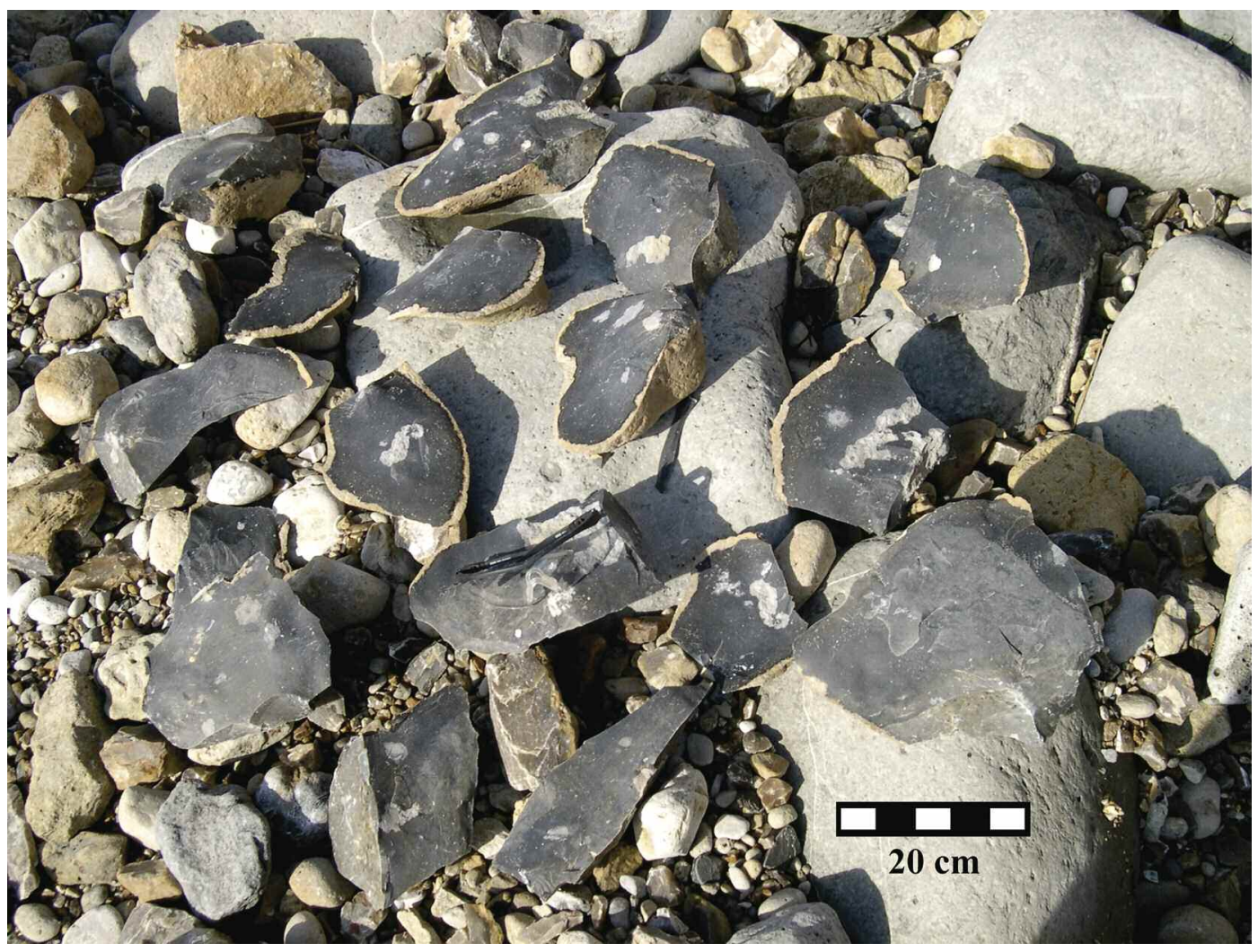

Figure 5. Selection of large flake blanks used for Levallois Tortoise Core (LTC) reduction. Differences between their measured morphologies (length/width, width/thickness, length/thickness) were not statistically significant. 
Table 2. Results of Two-Sample T-Tests Comparing Core Size and Shape between Pairs of 25-Core Lots (Alpha-Level $=.05$ ).

\begin{tabular}{|c|c|c|c|c|c|}
\hline Mass & Cores Sets & $\# 1-25$ & $\# 26-50$ & $\# 51-75$ & \#76-100 \\
\hline & $\# 1-25$ & - & - & - & - \\
\hline & \#26-50 & $\mathrm{p}=.2024$ & - & - & - \\
\hline & $\# 51-75$ & $\mathrm{p}=.9766$ & $\mathrm{p}=.2120$ & - & - \\
\hline & \#76-100 & $p=.0452$ & $p=.0057$ & $p=.0432$ & - \\
\hline \multirow[t]{5}{*}{$\mathrm{L}: \mathrm{W}$} & Cores Sets & $\# 1-25$ & \#26-50 & \#51-75 & $\# 76-100$ \\
\hline & $\# 1-25$ & - & - & - & - \\
\hline & \#26-50 & $\mathrm{p}=.9769$ & - & - & - \\
\hline & $\# 51-75$ & $\mathrm{p}=.5594$ & $\mathrm{p}=.6105$ & - & - \\
\hline & \#76-100 & $\mathrm{p}=.4742$ & $\mathrm{p}=.5226$ & $\mathrm{p}=.8368$ & - \\
\hline \multirow[t]{5}{*}{ W:T } & Cores Sets & $\# 1-25$ & $\# 26-50$ & $\# 51-75$ & $\# 76-100$ \\
\hline & $\# 1-25$ & - & - & - & - \\
\hline & \#26-50 & $\mathrm{p}=.0132$ & - & - & - \\
\hline & $\# 51-75$ & $\mathrm{p}=.0837$ & $\mathrm{p}=.3782$ & - & - \\
\hline & \#76-100 & $\mathrm{p}=.1922$ & $\mathrm{p}=.1898$ & $\mathrm{p}=.6518$ & - \\
\hline \multirow[t]{5}{*}{$\mathrm{L}: \mathrm{T}$} & Cores Sets & $\# 1-25$ & $\# 26-50$ & $\# 51-75$ & $\# 76-100$ \\
\hline & $\# 1-25$ & - & - & - & - \\
\hline & \#26-50 & $\mathrm{p}=.0475$ & - & - & - \\
\hline & \#51-75 & $\mathrm{p}=.2912$ & $\mathrm{p}=.3279$ & - & - \\
\hline & \#76-100 & $\mathrm{p}=.5439$ & $\mathrm{p}=.1999$ & $\mathrm{p}=.7001$ & - \\
\hline
\end{tabular}

The last lot (\#76-100) is statistically smaller than those preceding it (bold). Core morphology was similar throughout, except for a random increase in thickness of cores \#26-50 over cores \#1-25.

Department of Archaeology, University of Exeter, Exeter. Due to the sheer mass of the entire experimental data set $(171,773.5 \mathrm{~g})$, a future permanent storage facility is being sought.

\section{Results}

We use statistical alpha levels here for comparative and analytical purposes. We recognize LTC and PLF traits yielding a statistical alpha level below .20 as "blunt skill-level markers," while those yielding an alpha level below .05 are "sensitive skill-level markers." We stress that the one in five chance presented by the blunt skill-level marker is not intended to be statistically significant, only a marker for examination and discussion. We leave interpretations of statistical significance only to the sensitive skill-level marker.

\section{PLF Area as a Percent of Core Surface}

It takes the utmost skill to detach a PLF that removes most of the tortoise core's prepared ventral surface without overshooting the edge. Our expectation was that Bradley would on average remove more of the ventral surface than Eren. Bradley removed on average 38 percent of the prepared core surface $(n=20)$ in the 1970s and 48.4 percent in his recent sample $(n=5)$. A two-sample $t$-test shows no statistical difference $(t=1.2639 ; \mathrm{df}=4 ; p=.2749)$. Thus Bradley's combined score was 40 percent $(n=25)$, while Eren's was 34 percent $(n=100)$, the difference between them recognizable as a blunt skilllevel marker $(t=1.4089 ; \mathrm{df}=24 ; p=.1718)$. The same test applied to Bradley's recent score (48.4 percent, $n=5$ ) vs. Eren's (34 percent, $n=100$ ) again indicated PLF area percentage as a blunt skill-level $\operatorname{marker}(t=1.8512 ; \mathrm{df}=4 ; p=.1379)$.

Eren's surface area scores did not rise over the course of three months. Two-sample $t$-tests show no statistical difference in surface area from his first 10 cores vs. the last 10 cores $(t=.2606 ; \mathrm{df}=9 ; p$ $=.8003)$, the first 25 cores vs. the last 25 cores $(t$ $=.3896 ; \mathrm{df}=24 ; p=.7003)$, or the first 50 cores vs. the last 50 cores $(t=.3728 ; \mathrm{df}=49 ; p=.7109)$. 


\section{Overshots}

Bradley committed no overshots in his 1970s sample and only one (the first attempted core) in his recent set, for a combined overshot score of 4 percent. Whereas Eren ruined 20 percent of his cores. A chi-squared test indicates that this difference might be somewhat indicative of a sensitive skilllevel marker since it approached statistical significance $\left(\chi^{2}=3.6630 ; \mathrm{df}=1 ; p=.0556\right)$.

We were interested in whether Eren's overshot rate had declined with experience, but it did not. Figure 4 shows bursts of overshots punctuated by runs of properly constrained strikes. Chi-squared tests show no improvement when the whole run is grouped by sets of 10 cores $\left(\chi^{2}=8.1811\right.$; df $=9$; $p=.5160)$, sets of 25 cores $\left(\chi^{2}=2.5518 ; \mathrm{df}=3\right.$; $p=.4660)$, or sets of 50 cores $\left(\chi^{2}=.2501 ; \mathrm{df}=1\right.$; $p=.6170)$. Over the course of the three-month experiment Eren continued to commit overshots.

Bradley's unique overshot at the start of his fivecore run is instructive because he had not made LTCs for a couple of months and was in a hurry. He knew that the first core needed more ventral and dorsal removals to be fully set up and that there was a good chance of an overshot, but he took the chance anyway and hit it. In subsequent reductions he took the time needed. Note that Eren's overshots do not follow hiatuses between his knapping runs (Figure 4).

\section{PLF Surface Area Without Overshots}

Assigning zero values to PLF overshots distorts all averaged PLF surface area scores, reviewed above. If we treat overshots as "noise" and exclude them from the comparisons, Bradley's PLFs averaged 60.5 percent of core surface area for his recent sample $(n=4)$, a marked improvement over his 38 percent score of 30 -odd years ago $(n=20)$. Although a two-sample $t$-test indicates that this difference is statistically significant $(t=5.9710 ; \mathrm{df}=3 ; p=$ .0094), his recent sample is very small. However, we doubt that his score would drop much if he had expanded his recent production run to, say, 20 cores. As it stands, his combined PLF sample without the overshot $(n=24)$ yields an average score of 42.1 percent.

This is no different from Eren's score of 43 percent for his overshot-free sample $(n=80)$, since $p=.7888(t=.2710 ; \mathrm{df}=23)$ in this comparison. Unsurprisingly, there is a significant difference ( $t=7.9842 ; \mathrm{df}=3 ; p=.0041)$ between Bradley's new $(n=4)$ sample and Eren's $(n=80)$ sample, but Bradley's small sample size again blurs the comparison.

With the overshots removed, there is still no statistically significant difference in Eren's first 10 cores vs. the last 10 cores $(t=.4394 ; \mathrm{df}=6 ; p=$ $.6757)$, the first 25 cores vs. the last 25 cores $(t=$ .4963 ; df $=18 ; p=.6257)$, or the first 50 cores vs. the last 50 cores $(t=.0971$; df $=38 ; p=.9235)$. This confirms that there was no measurable improvement in Eren's ability to detach more of the core's ventral surface area, even with overshots discounted.

\section{PLF Symmetry (Eccentricity)}

If it is difficult to remove most of the LTC's ventral surface with one blow, it is an even more delicate business to get its margin to detach just inside the core's rim. Our expectation was that Bradley's first PLF would more consistently follow the rim of the ventral surface than Eren's.

There is a statistically significant difference ( $t=10.7958 ; \mathrm{df}=3 ; p=.0017$ ) between Bradley's symmetry scores for his pioneer LTC sample of $n=19$ (one drawing is missing) and his recent one $(n=4)$. While this suggests that Bradley improved his Levallois ventral preparation since the 1970s, we are again bedeviled by the small sample size of his recent output.

PLF symmetry comparisons between Eren $(n=$ $80)$ and Bradley $(n=23)$ meet expectations: a twosample $t$-test suggests that PLF symmetry is a blunt skill-level marker since $p=.0898(t=1.7746$; $\mathrm{df}=$ 22 ). However, when one asymmetrical outlier is removed from Bradley's total sample, a two-sample $t$-test suggests that indeed PLF symmetry is a sensitive skill-level marker, since $p=.0107(t=$ 2.8012; df = 21).

Eren's symmetry values did not improve (decrease) over the three-month trial. Two-sample $t$-tests show that there is no statistical difference in his first 10 cores vs. his last 10 cores $(t=.9354$; $\mathrm{df}=9 ; p=.3740)$, the first 25 cores vs. the last 25 cores $(t=.0139 ; \mathrm{df}=24 ; p=.9890)$, or the first 50 cores vs. the last 50 cores $(t=.0082$; $\mathrm{df}=49 ; p=$ $.9935)$. The statistical results do not change if overshot flakes are included.

\section{Economy of Core Preparation}

When readying the tortoise core's ventral surface 

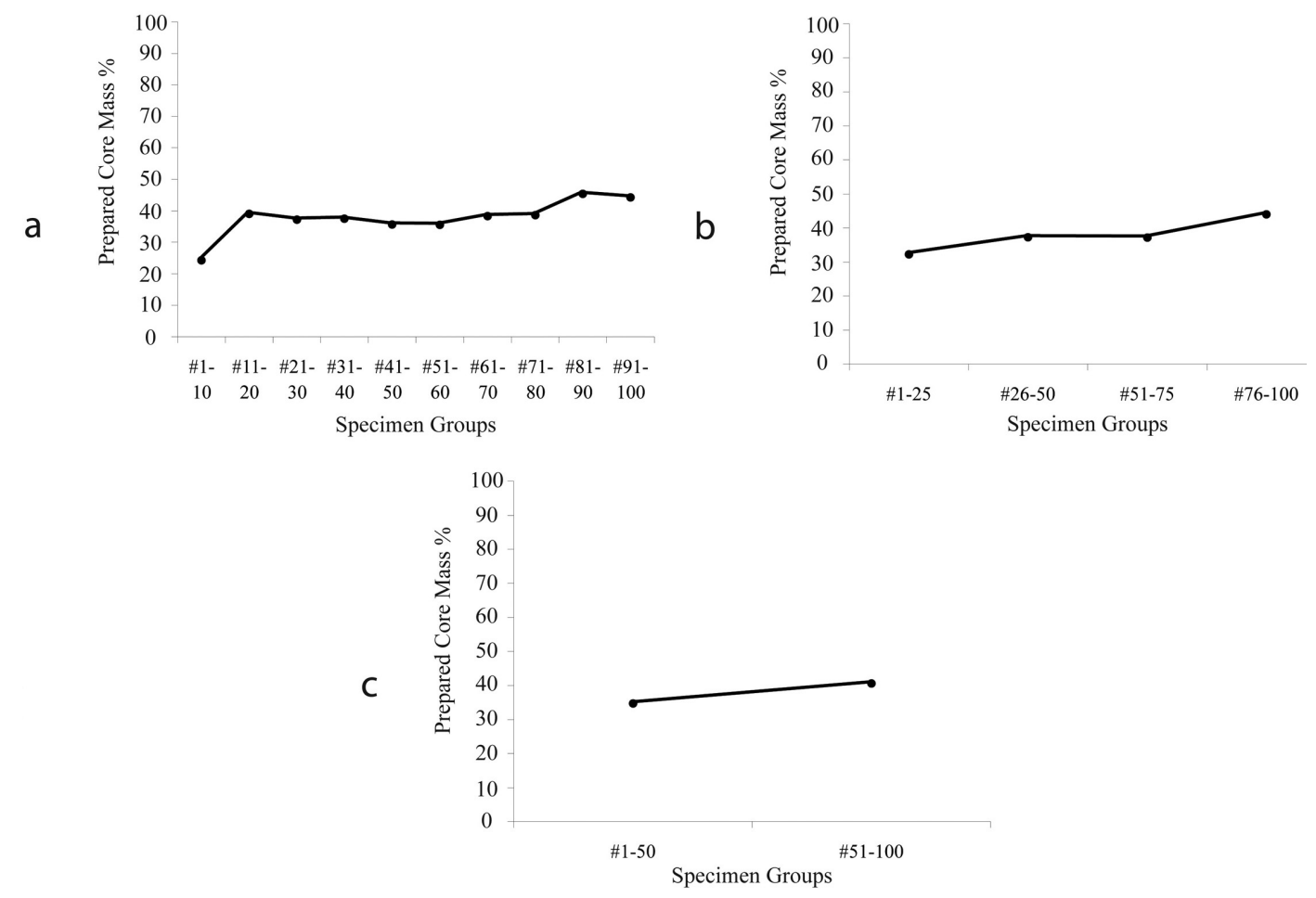

Figure 6. Mean prepared core mass (g) as a percentage of the unmodified large flake mass over the course of 100 LTC's, depicted by (a) every 10 cores; (b) every 25 cores; and (c) every 50 cores.

there comes a moment when the knapper decides that its convexity is just right, the platform may be readied, and the PLF struck. It takes an experienced knapper fewer blows and less time to perfect that convexity, while a beginner struggles longer and fusses more over getting the face just right. It would be reasonable to assume, then, that Bradley would consume less stone than Eren in setting up his cores.

Appropriate data are available only for Bradley's recent sample. These are relatively small blanks. The combined mass of his five chosen blanks was 2,687 $\mathrm{g}$, and his readied cores (before the PLF removal) totaled $1,300 \mathrm{~g}$. Thus he used up $1,387 \mathrm{~g}$ (51.6 percent) of his blanks to attain the correct core configuration, and his average prepared core mass is 48 percent of original blank mass.

The total weight of Eren's more numerous blank sample $(n=100)$ was $171,773 \mathrm{~g}$, and his readied cores together weighed 61,285 g. Overall, Eren consumed 110,488 g (64 percent) of his blank mass, and his readied cores comprise 36 percent of his blank mass. A two-sample $t$-test comparing their averages indicates that the difference between them is statistically significant $(t=15.5441 ; \mathrm{df}=4 ; p<$ $.0001)$, suggesting that economy of core preparation is a highly sensitive marker of skill level.

In this test, Eren's experimental data show clear signs of growing confidence. There is a steady increase of prepared core mass in relation to the unmodified blank mass, as shown in Figure 6. The moment at which he deemed the surface convexity ready to be struck came progressively earlier in the reduction sequence, as he worked his way through the 100 cores. It follows that he used up less and less raw material as he set up the core face. A two-sample $t$-test shows that there is a statistically significant difference in the first 10 cores vs. the last 10 cores $(t=3.4565 ; \mathrm{df}=9 ; p=.0072)$, the first 25 cores vs. the last 25 cores $(t=3.4875$; $\mathrm{df}=$ $24 ; p=.0019)$, and the first 50 cores vs. the last 50 cores $(t=2.5458 ; \mathrm{df}=; p=.0141)$.

\section{Economy of Dorsal Surface Preparation}

Expectations are that Bradley would remove less of the core's dorsal surface during core setup than Eren. Again, data for mass weights of Bradley's 

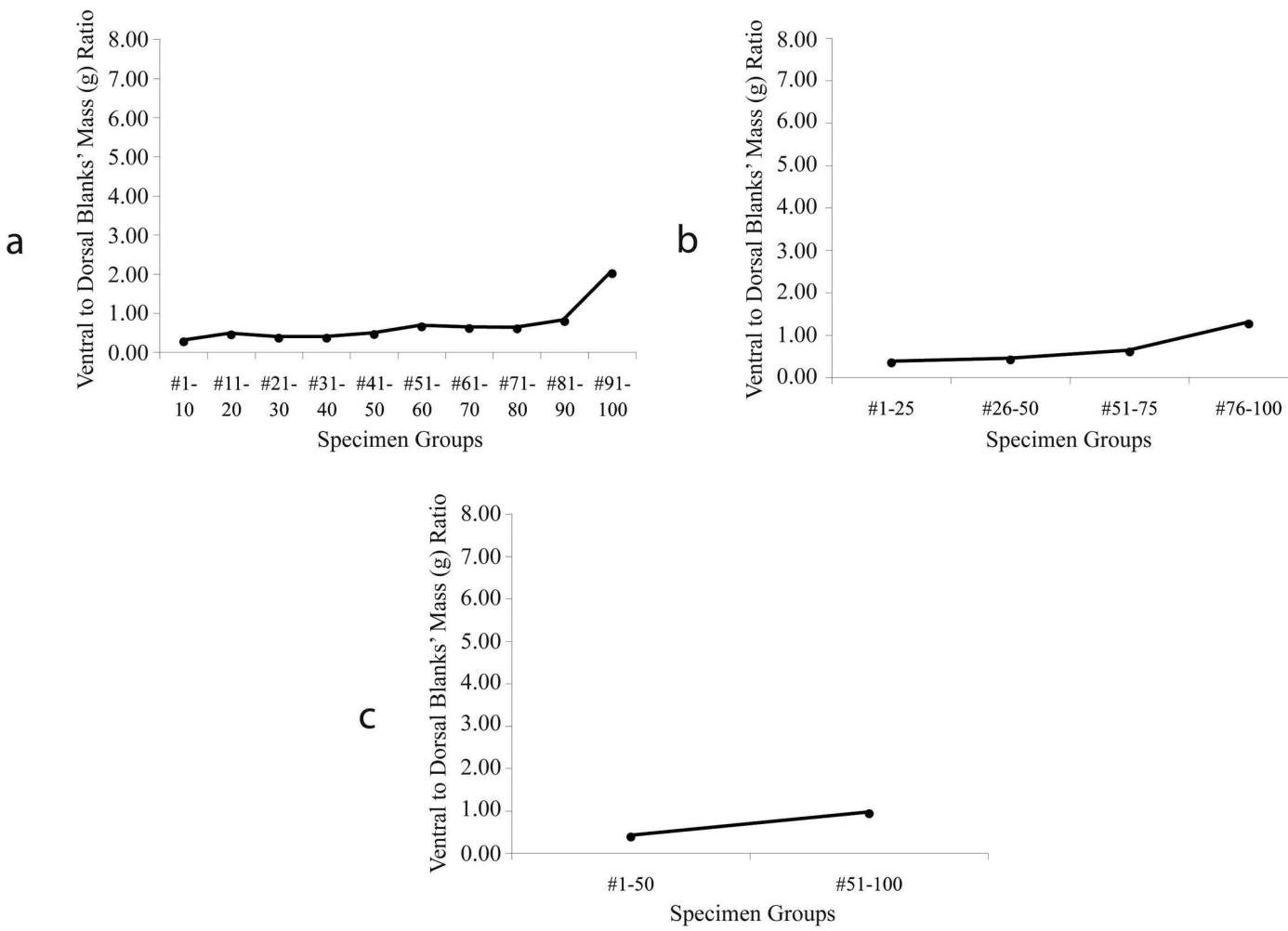

Figure 7. Mean ventral/dorsal flake mass ratio over the course of 100 LTC's, depicted by (a) every 10 cores; (b) every 25 cores; and (c) every 50 cores.

ventral and dorsal flakes are available only for his recent sample $(n=5)$. His combined ventral flakes weigh $439 \mathrm{~g}$, while his dorsal flakes total $871 \mathrm{~g}$, for a summed ventral/dorsal ratio of .5. His average ventral/dorsal ratio is .54. By contrast, Eren's combined $(n=100)$ ventral flakes weighed 29,917 $\mathrm{g}$, and his dorsal flakes weighed $74,244 \mathrm{~g}$, so his summed ventral/dorsal ratio is .4 , and his averaged ventral/dorsal ratio is .65 . However, an extreme outlier (\#91) distorts the average, which drops to .54 when it is removed. Although comparison of the summed values hints that Bradley did indeed use up less of dorsal surface mass, the averaged values do not. A two-sample $t$-test comparing averaged ventral/dorsal ratio shows that the divergence is not significantly different $(t=1.1114 ; \mathrm{df}=4 ; p$ $=.3287)$. With the outlier removed they remain indistinguishable $(t=.0792 ; \mathrm{df}=4 ; p=.9407)$.

Eren's ventral to dorsal flake ratios again indicate an improving upward trend (Figure 7) over the course of 100 cores. The mass of his dorsal removals per core decreased significantly over time, while that of ventral removals rose. Two-sample $t$ tests show highly significant statistical differences in the ventral/dorsal ratios of the first 10 cores vs. the last 10 cores $(t=2.458 ; \mathrm{df}=9 ; p=.0363)$, the first 25 cores vs. the last 25 cores $(t=2.9937$; $\mathrm{df}=$ $24 ; p=.0063)$, and the first 50 cores vs. the last 50 cores $(t=3.3210 ; \mathrm{df}=49 ; p=.0017)$. All tests remained significant when the failed core \#91 was omitted. This documents growing confidence in the way he envisioned the core-to-be within the unshaped stone blank and developed this conceptual skill.

\section{Summary of Results}

Bradley and Eren were distinguished by their averaged PLF surface area scores, suggesting that this trait might indeed serve as a blunt skill-level marker. When overshots were excluded, however, their differences disappeared. Surface area percentages appear not to be independent indicators of skill level.

The two knappers were clearly distinguished by their overshot frequencies. This is at least a blunt 

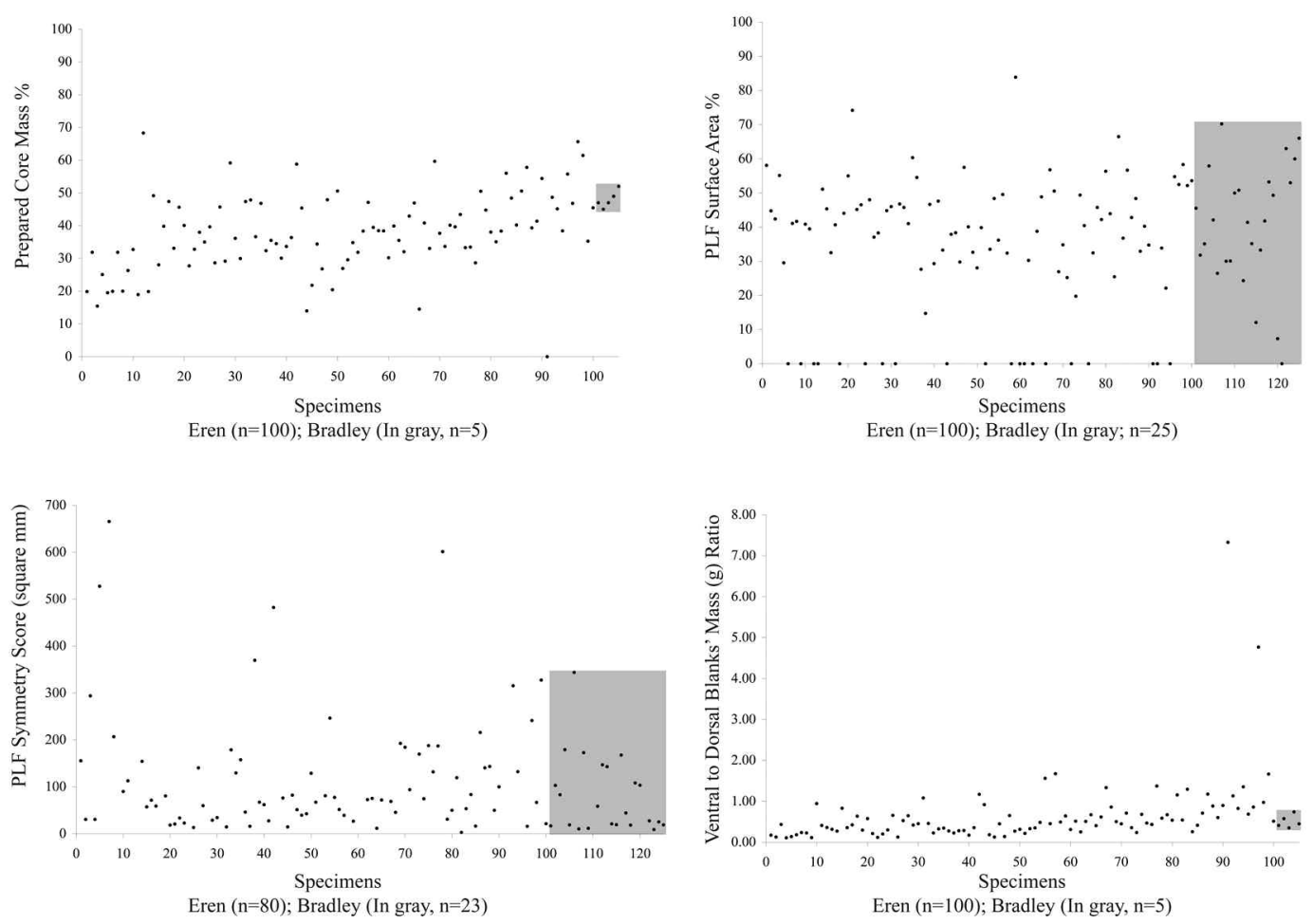

Figure 8. Raw data values for prepared core mass percentage, PLF surface area percentage, PLF symmetry score, and ventral/dorsal flake mass ratio. Bradley's scores are highlighted in gray; Eren's scores are not. Bradley's "mentor range" falls entirely within Eren "learner range" for each skill-level marker.

marker of skill, possibly a sensitive one. If many overshots of the first PLF occur in a Middle Paleolithic assemblage, it is probable that beginners were present.

The handiwork of Bradley and Eren could also be distinguished by their averaged first PLF symmetry scores. As a blunt, verging on sensitive, skilllevel marker, the presence of many highly symmetrical PLFs in a Middle Paleolithic assemblage suggests that experienced knappers were at work. Large numbers of very eccentric PLFs appear to be sound indicators of early-stage learners at work.

It is likely that experienced knappers can also be distinguished from learners by their averaged total mass consumption during core production, but near-complete sets of refits would be needed to determine this in the prehistoric record, making it difficult to employ this quite sensitive skill-level marker. Large numbers of complete refits yielding high debitage mass would point to the presence of early-stage learners, while a few might signal latestage learners.
Averaged ratios of ventral/dorsal flakes appear to be insensitive as markers of knapping experience. Yet there is clear evidence that Eren's conception and approach to the ventral and dorsal surfaces evolved significantly over the three-month experiment. At the very least, Eren's ventral/dorsal flake ratios document a knapper's individual and evolving understanding of his craft.

\section{Discussion}

\section{Averaged vs. Raw Results}

Excepting overshots, the other four potential markers of skill level for Levallois tortoise core production are all based on averaged data. If we leave those same data unaveraged (Figure 8), their usefulness as markers all but disappears. For example, PLF surface area (as a percentage of core surface area), already shown to be a marginal skill marker, is much discredited when unaveraged. The two highest-scoring PLFs in the entire experiment are 74 percent and 84 percent of core surface area. 
These are so far above either sample average that we might be excused for supposing they were from Bradley, although they both come from Eren's sample. If these two specimens were found on an archaeological site, we might similarly be forgiven for supposing that they were the handiwork of a highly skilled knapper.

Again, Bradley's PLFs are, on average, significantly more symmetrical than those of Eren, but the most symmetrical flake of the entire experiment $(n=123)$ comes from Eren $\left(3.12 \mathrm{~mm}^{2}\right)$. Of the 25 most symmetrical PLFs in the combined experiment, Bradley produced 12 and Eren produced 13. Clearly, a single highly symmetrical PLF in an archaeological context cannot be reliably ascribed to any particular skill level.

The problem with averaged data is that they force us to assume that the prehistoric knapper always performed at his or her optimum skill level. This is an unreasonable assumption (Bamforth and Finlay 2008). Even when a knapper's intention is to perform optimally, as was the case with both experimental data sets, factors as mundane as simply "having a bad day" or being "out of practice" or "in a hurry" (e.g., Bradley's first overshot) may have tremendous influence on assemblage formation and appearance-despite tight control over other variables. For example, on April 25, Eren's experimental core specimens \#93, \#94, \#95, and \#96 were knapped with PLF surface areas of 34, 22, 0 (overshot), and 55 percent, respectively. Thus, the average PLF surface area for that (bad) day was 28 percent. The very next day (his last), core specimens \#97, \#98, \#99, and \#100 were knapped with notable consistency, and PLF surface area scores were $52,58,52$, and 54 percent, for an average of 54 percent - nearly double that of the previous day. The consistency of this run is quite comparable to that of Bradley's recent sample with scores of 63, 53,60 , and 66 percent, following his unique overshot.

Consistency of output is widely acknowledged by modern knappers to grow with experience, and high consistency is widely held to be a hallmark of the master knapper. Although axiomatic, this remains to be properly tested. Consistency is best reflected in the range of values, rather than their average. For example, the range of prepared core mass (as a percentage of blank mass) of Bradley's single short run is only 7 percent, compared with
Eren's 21 percent range on his last day. Over Eren's whole learning trajectory, his range was 54 percent, if we omit the one failed preparation. Likewise the range of Bradley's ventral/dorsal flake ratio is only .39 compared to Eren's last day at 4.26. Eren's overall range was 4.66, again omitting the single preparation failure. PLF surface and symmetry exhibit these same patterns (Figure 8).

Although this looks promising, the trouble here is that Bradley's data invariably fall entirely inside the wider range of Eren's - they overlap completely (Figure 8). None of these apparent markers for skill level can be applied individually. We need another approach that combines them.

\section{Mentor/Learner Threshold Values}

Excepting a few outliers, the lowest value obtained by Bradley in each test can be used as a threshold value that defines his least successful performance. Any of Eren's scores that fall below the threshold value for that test may be reasonably taken to mark the work of a learner.

Bradley's minimal scores, with noted outliers, are as follows: $179 \mathrm{~mm}$ for PLF symmetry (one outlier excluded); 24 percent for the PLF surface area percentage (two outliers excluded); 0 for overshots (one outlier excluded); 45 percent for prepared core mass percentage (no outliers); .35 for ventral/dorsal flake mass ratio (no outliers). Recall that the last two values are based on only five reductions and are therefore set unfairly high.

Figure 9 summarizes all reductions and tests where Eren's score fell below the threshold value. An equivalent diagram for Bradley would be blank except for the four outliers listed above, and 20 each of his red and blue cells (Figure 9) would contain "no data" (nd) entries. The orderly decline in Eren's ventral/dorsal flake mass ratio "failures" shows up clearly (red) in spite of the unfairly high threshold setting. His high "failure" rate for core mass percentage (dark blue) diminishes later in the 100core sequence, although we know that he improved steadily (see above). This improving trend would become clearer in Figure 9 if we lowered the threshold value. No such declines in failure rates are visible among the PLF measures, but the early run of asymmetric flakes (green) is noteworthy. Also notable is the rarity of his small-area PLFs, a neat complement to his repeated overshots, and both signaling that he continued to use rather too much 


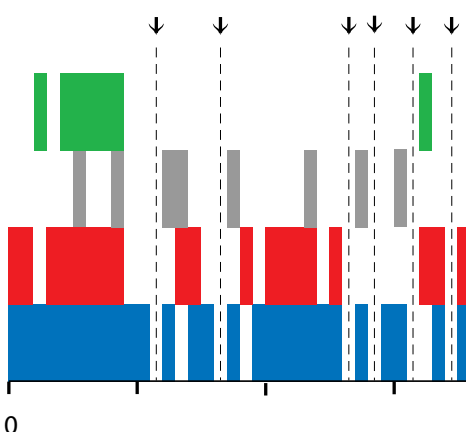

0

Ventral/dorsal flake mass ratio exceeds 0.35

Core mass less that $45 \%$ of blank mass

\section{MIDDLE PALEOLITHIC SKILLLLVEL}

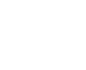

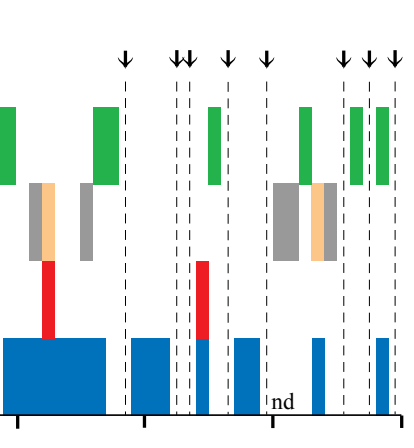

50

PLF area below 24\% of core's ventral surface

Overshot

\section{0}

PLF Symmetry above $179 \mathrm{~mm}^{2}$

$\downarrow \quad$ Reduction passed all tests

Figure 9. Sub-threshold scores for Eren's 100 Levallois tortoise core reductions. Threshold values (Bradley's skill minima) are shown in the key below. Arrows denote reductions that cannot be distinguished from those of Bradley.

force throughout, a typical learner's disability (Grimm 2000).

The more surprising outcome of this approach is that no less than 18 of his reductions "passed" all five tests (Figure 9, vertical arrows) and cannot be distinguished from the handiwork of his mentor, Bradley. This number would certainly be higher if those unfair core preparation thresholds were lowered. The increasing frequency of mentor-level reductions toward the end of Eren's sequence displays how the various skills needed are beginning to amalgamate, heralding mastery of LTC production in the near future.

\section{Conclusions}

Our system of measurements needs more work and is never likely to reach perfection. Although it correctly identifies 82 percent of a large run of learnermade Levallois tortoise core reductions, it misclassifies 18 percent as mentor-made. Furthermore, the threshold values (mentor's minima) for two of the system's tests are derived from just five mentor-made reductions and are set too high. If we could lower them (using larger samples), the system would misclassify even more reductions as mentor-made. We can only guess the system's real success rate, which may be around 70 percent, perhaps lower. For the smaller mentor's sample, 84 percent are correctly identified, but having only partial data for 20 reductions means that the actual success rate also will be lower, perhaps much lower. To correct this methodological flaw we must generate a larger mentor-made sample with which to set more realistic threshold values. When this is done we shall be better able to predict rates at which early-learner reductions (with core-preparation tests failed) can be correctly distinguished from late-learner reductions (core-preparation tests passed).

The misclassifications derive from another inherent design flaw: we took it on trust that learning (refining) Levallois involves a steady honing of skills. The experiment's real contribution, probably of more lasting value than its results, is that it refutes our untested prior assumption. Learning Levallois does not proceed by the gradual acquisition of skills. It is more like learning to ride a bicycle: at first we fall over repeatedly, until suddenly we go solo for a few seconds before tipping over once more. During that short ride we resemble any other accomplished cyclist_-brain and body have meshed to keep balance. It is only the wobbling and tipping episodes that identify us as learners; the upright moments do not. Early on there is much wobbling and many spills; later the wobbling diminishes, and spills become infrequent. Eren's learning trajectory progressed along a similar path-when the experiment began he had already passed the "fall over repeatedly" stage and was 
producing wildly eccentric PLFs from LTCs shaped with much debitage lost, most of it from the dorsal preparation (heavy wobbling). Quite unexpectedly his eleventh reduction produced a core and flake within Bradley's ranges (the biker goes solo), then his next two were overshots (bike tips over again), and so on (Figure 9).

We also note in passing that it took longer for Eren to master Levallois reduction than it took him to learn to ride a bicycle when just seven years old. Hawcroft and Dennell (2000) raise the intriguing possibility that children might learn flintknapping faster than adults and that a Neanderthal child, undergoing more rapid physical and mental development than modern humans, would have learned even faster. Shea (2006) already advocates the creation of middle-range data sets involving children's flintknapping, and this project might provide a suitable focus for such comparisons (see also Johansen and Stapert 2008; Stapert 2007; Sternke and Sorensen 2009).

Meanwhile, our system must go back to the drawing board to be redesigned around our new understanding of the learning pathway. It may be that the discovery of yet more skill-level measures will reduce the number of misclassified reductions, but we are doubtful, not only of our ability to find them but of their effectiveness. Instead, we intend to explore measures of personal style, in this case unconscious motor habits, and if possible to incorporate them in the design, always mindful that they may overlap with skill-level measures in unpredictable ways (Bamforth and Finlay 2008). Taking our example from Stout (2002), we plan to greatly expand our investigation of symmetry, both PLF and core symmetries and also the extent to which PLF shape conforms to the rim of the LTC.

\section{Limitations for the Archaeological Record}

Presented with a completely refitted LTC reduction from a pristine context (e.g., rapid and gentle burial in fine sediment or volcanic ash) we may make our key measurements on the first PLF and on the rebuilt core and then state with $<70$ percent certainty whether it was made by a learner or by a more experienced person. Presented with seven such contiguous clusters, let us suppose that three of the refits produce multiple below-threshold scores and that four others score uniformly above the threshold in all measures. Were they produced by two knappers? Or by one knapper on a good and a bad day, or month, or year (and thus at two different moments in his or her learning trajectory)? Archaeology lacks the means to distinguish the small time lapses between flake clusters on the same floor. Even if some other (yet-to-be-discovered) marker, unrelated to skill level, pointed to both clusters coming from the same knapper's hand, we could not even be certain which was the first one executed.

Any further judgment must involve spatial analysis as well. If the skill-level measurements from a pair of adjacent clusters are very similar, perhaps nearly identical, the chances increase that they were produced by the same knapper, but even here a residual doubt lingers. The case for a lone knapper is stronger if the floor yielded seven same-skill clusters, but the odds of finding such is remote. Were we to suppose two or three times this number of refitting LTC reductions on one surface (well beyond anything currently on record), we can foresee that rising sample size will only increase between-cluster variations, even if one knapper made all. An ideal situation might be a floor yielding scores of refittable LTC reductions forming spatial clusters each with its own standardized skill level. To produce such a pattern the Middle Paleolithic knappers responsible would have to be amazingly consistent performers, not (yet) demonstrated by a modern knapper in a controlled experiment. Until computerized refitting becomes a reality, the task of refitting so many reductions will require superhuman effort.

The system is nowhere near ready to be applied to Middle Paleolithic assemblages in derived contexts and with no refits. At sites some distance from raw material (the vast majority), it will be extremely difficult to identify first PLFs from later ones in the reduction sequence. Also, the LTC will be wholly reduced and much smaller than the ones used in this experiment. Overshots will be the only useful markers for learners. Until we have worked on control samples for the later stages in the LTC reduction, we cannot be certain that comparable threshold values will apply.

At those rare sites close to a rock source where reductions are incomplete, the LTC and the first PLF can be identified and measured, but only three of the tests can be applied. When we do this to the combined experimental sample $(n=125)$, we end up with 83 (66.4 percent) mentor-made cores that 
pass all three tests and 42 (33.6 percent) learnermade cores. This is so far from the actual proportion of learner-made cores ( 80 percent) that it is clearly worthless. The three PLF tests are not enough to distinguish the products of experienced knappers from the erratic successes of learners. We can state categorically that there were learners present, but we cannot say how many. This is the absolute limit to which our quest for individuals in most derived assemblages may be pursued via skill level alone.

Acknowledgments. Funding for Metin I. Eren was provided by a National Science Foundation Graduate Research Fellowship; Mustafa, Kathleen, and Nimet Eren; and the Exeter Graduation Fund. Thanks go to Tony Baker, Ryan Byerly, Rebecca Catto, Linda Hurcombe, Mark Kollecker, David Meltzer, Alan Outram, Alison Rautman, Brian Redmond, and four anonymous reviewers for comments on an earlier version of the text. Thanks go to Mike Rouillard and Sean Goddard for photography instruction and equipment, Aaron Greenspan and the Think Computer Corporation for technical support, and Carolina Mallol for translating the abstract into Spanish. We take sole responsibility for any mistakes.

\section{References Cited}

Andrews, Bradford

2003 Measuring Prehistoric Craftsman Skill. In Mesoamerican Lithic Technology: Experimentation and Interpretation, edited by Kenneth Hirth, pp. 208-219. University of Utah Press, Salt Lake City.

Apel, Jan

2008 Knowledge, Know-How, and Raw Material-The Production of Late Neolithic Flint Daggers in Scandinavia Journal of Archaeological Method and Theory 15:91-11.

Bamforth, Douglas B., and Nyree Finlay

2008 Introduction: Archaeological Approaches to Lithic Production Skill and Craft Learning. Journal of Archaeological Method and Theory 15:1-27.

Bamforth, Douglas B., and Keri Hicks

2008 Production Skill and Paleoindian Workgroup Organization in the Medicine Creek Drainage, Southwestern Nebraska. Journal of Archaeological Method and Theory 15:132-153.

Bleed, Peter

2008 Skill Matters. Journal of Archaeological Method and Theory 15:154-166.

Boeda, Eric

1995 Levallois: A Volumetric Construction, Methods, a Technique. In The Definition and Interpretation of Levallois Technology, edited by Harold Dibble and Ofer BarYosef, pp. 41-68. Monographs in World Archaeology No. 23. Prehistory Press, Madison.

Bordes, François

1961 Typologie du Paléolithique ancien et moyen. Delmas, Bordeaux.

Bradley, Bruce

1977 Experimental Lithic Technology with Special Reference to the Middle Paleolithic. Unpublished Ph.D. disser- tation, Department of Archaeology, University of Cambridge.

Brantingham, P. Jeffrey, and Steven L. Kuhn

2001 Constraints on Levallois Core Technology: A Mathematical Model. Journal of Archaeological Science 28:747-761

Chazan, Michael

1997 Redefining Levallois. Journal of Human Evolution 33:719-735.

Close, Angela E

1989 Identifying Style in the Stone Artefacts: A Case Study from the Nile Valley. In Alternative Approaches to Lithic Analysis, edited by Donald Henry and George Odell, pp. 3-26. University of Tulsa, Tulsa.

Costin, Cathy L., and Melissa B. Hagstrum

1995 Standardization, Labor Investment, Skill, and the Organization of Ceramics Production in Late Prehistoric Highland Peru. American Antiquity 60:619-639.

Dibble, Harold L., and Ofer Bar-Yosef (editors)

1995 The Definition and Interpretation of Levallois Technology. Monographs in World Archaeology No. 23. Prehistory Press, Madison

Dobres, Marcia-Anne

2000 Technology and Social Agency. Blackwell, Oxford.

Eren, Metin I., and Bruce A. Bradley

2009 Experimental Evaluation of the Levallois "Core Shape Maintenance" Hypothesis. Lithic Technology 34(2), Fall: 119-125.

Eren, Metin I., Aaron Greenspan, and C. Garth Sampson

2008 Are Upper Paleolithic Blade Cores More Productive than Middle Paleolithic Discoidal Cores? A Replication Experiment. Journal of Human Evolution 55:951-961.

Ferguson, Jeffrey

2003 An Experimental Test of the Conservation of Raw Materials in Flintknapping Skill Acquisition. Lithic Technology 28(2):11-131.

2008 The When, Where, and How of Novices in Craft Production. Journal of Archaeological Method and Theory 15:51-67.

Finlay, Nyree

1997 Kid Knapping: The Missing Children in Lithic Analysis. In Invisible People and Processes: Writing Gender and Childhood into European Archaeology, edited by Jenny Moore and Eleanor Scott, pp. 203-212. Leicester University Press, London.

2008 Blank Concerns: Issues of Skill and Consistency in the Replication of Scottish Later Mesolithic Blades. Journal of Archaeological Method and Theory 15:68-90.

Gamble, Clive, and Martin Porr

2005 From Empty Spaces to Lived Lives: Exploring the Individual in the Palaeolithic. In The Hominid Individual in Context: Archaeological Investigations of Lower and Middle Palaeolithic Landscapes, Locales, and Artefacts, edited by Clive Gamble and Martin Porr, pp. 1-12. Routledge, New York.

Grimm, Linda

2000 Apprentice Flintknapping: Relating Material Culture and Social Practice in the Upper Palaeolithic. In Children and Material Culture, edited by Joanna S. Derevenski, pp. 53-71. Routledge, New York.

Hawcroft, Jennie, and Robin Dennell

2000 Neanderthal Cognitive Life History and Its Implications for Material Culture. In Children and Material Culture, edited by Joanna Sofaer Derevenski, pp. 89-99. Routledge, New York.

Hill, James N., and Joel Gunn

1977 Introducing the Individual in Prehistory. In The Indi- 
vidual in Prehistory: Studies of Variability in Style in Prehistoric Technologies, edited by James Hill and Joel Gunn, pp. 1-12. Academic Press, New York.

Hogberg, Anders

2008 Playing with Flint: Tracing a Child's Imitation of Adult Work in a Lithic Assemblage. Journal of Archaeological Method and Theory 15:112-131.

Hopkinson, Terry, and Mark J. White

2005 The Acheulean and the Handaxe. In The Hominid Individual in Context: Archaeological Investigations of Lower and Middle Palaeolithic Landscapes, Locales, and Artefacts, edited by Clive Gamble and Martin Porr, pp. 13-28. Routledge, New York.

Johansen, Lykke, and Dick Stapert

2008 Stone Age Kids and Their Stones. In Technology in Archaeology. Proceedings of the SILA Workshop: The Study of Technology as a Method for Gaining Insight into Social and Cultural Aspects of Prehistory, the National Museum of Denmark, Copenhagen, November 2-4, 2005 , edited by Pierre Desrosiers and Mikkel Sorensen, pp. 15-39. Publications from the National Museum, Studies in Archaeology and History, Vol. 14. National Museum of Denmark, Copenhagen.

Lyman, R. Lee, Todd L. VanPool, and Michael J. O'Brien

2008 Variation in North American Dart and Arrow Points When One or Both Are Present. Journal of Archaeological Science 35:2805-2812.

Machin, Anna

2009 The Role of the Individual Agent in Acheulian Biface Variability: A Multi-Factorial Model. Journal of Social Archaeology 9:35-58.

Milne, S. Brooke

2005 Palaeo-Eskimo Novice Flintknapping in the Eastern Canadian Arctic. Journal of Field Archaeology 30:329-345

Newcomer, Mark H.

1971 Some Quantitative Experiments in Handaxe Manufacture. World Archaeology 3:85-94.

Noble, William, and Iain Davidson

1996 Human Evolution, Language, and Mind: A Psychological and Archaeological Inquiry. Cambridge University Press, New York.

Ohnuma, Katsuhiko

1995 Analysis of Debitage Pieces from Experimentally Reduced "Classical Levallois" and "Discoidal" Cores. In The Definition and Interpretation of Levallois Technology, edited by Harold Dibble and Ofer Bar-Yosef, pp. 257-266. Monographs in World Archaeology No. 23. Prehistory Press, Madison.

Olausson, Deborah J.

2008 Does Practice Make Perfect? Craft Expertise as a Factor in Aggrandizer Strategies. Journal of Archaeological Method and Theory 15:28-50.

Petraglia, Michael D., Ceri Shipton, and K. Paddayya

2005 Life and Mind in the Acheulean: A Case Study from India. In The Hominid Individual in Context: Archaeological Investigations of Lower and Middle Palaeolithic Landscapes, Locales, and Artefacts, edited by Clive Gamble and Martin Porr, pp. 197-219. Routledge, New York.

Plog, Fred

1977 Archaeology and the Individual. In The Individual in Prehistory: Studies of Variability in Style in Prehistoric Technologies, edited by James Hill and Joel Gunn, pp. 13-21. Academic Press, New York.

Porr, Martin

2005 The Making of the Biface and the Making of the Individual. In The Hominid Individual in Context: Archaeo- logical Investigations of Lower and Middle Palaeolithic Landscapes, Locales, and Artefacts, edited by Clive Gamble and Martin Porr, pp. 68-80. Routledge, New York.

Proctor, Robert W., and Addie Dutta

1995 Skill Acquisition and Human Performance. Sage Publications, Thousand Oaks

Read, Dwight

2006 Tasmanian Knowledge and Skill: Maladaptive Imitation or Adequate Technology? American Antiquity 71:164-184

Redman, Charles L.

1977 The "Analytical Individual" and Prehistoric Style Variability. In The Individual in Prehistory: Studies of Variability in Style in Prehistoric Technologies, edited by James Hill and Joel Gunn, pp. 41-53. Academic Press, New York.

Rick, John

1996 Projectile Points, Style, and Social Process in the Preceramic of Central Peru. In Stone Tools: Theoretical Insights into Human Prehistory, edited by George Odell, pp. 245-278. Plenum Press, New York

Roux, Valentine, Blandine Bril, and Gregory Dietrich

1995 Skills and Learning Difficulties Involved in Stone Knapping: The Case of Stone-Bead Knapping in Khambhat, India. World Archaeology 27:63-87.

Sandgathe, Dennis M.

2004 Alternative Interpretation of the Levallois Reduction Technique. Lithic Technology 29:147-159.

2005 Examining the Levallois Reduction Strategy from a Design Theory Point of View. BAR International Series 1417. British Archaeological Reports, Oxford.

Schick, Kathy D.

1994 The Movius Line Reconsidered: Perspectives on the Earlier Palaeolithic of Eastern Asia. In Integrative Paths to the Past: Paleoanthropological Advances in Honor of F. Clark Howell, edited by Robert S. Corruccini and Russell L. Ciochon, pp. 569-595. Prentice Hall, Englewood Cliffs, New Jersey.

Schlanger, Nathan

1996 Understanding Levallois: Lithic Technology and Cognitive Archaeology. Cambridge Archaeological Journal 6:231-254.

Sellet, Frederic

1995 Levallois or Not Levallois, Does It Really Matter? Learning from an African Case. In The Definition and Interpretation of Levallois Technology, edited by Harold Dibble and Ofer Bar-Yosef, pp. 25-39. Monographs in World Archaeology No. 23. Prehistory Press, Madison.

Shea, John J.

2006 Child's Play: Reflections on the Invisibility of Children in the Paleolithic Record. Evolutionary Anthropology 15:212-216.

Shelley, Phillip H.

1990 Variation in Lithic Assemblages: An Experiment. Journal of Field Archaeology 17:187-193.

Sinclair, Anthony, and John McNabb

2005 All in a Day's Work: Middle Pleistocene Individuals, Materiality and the Lifespace at Makapansgat, South Africa. In The Hominid Individual in Context: Archaeological Investigations of Lower and Middle Palaeolithic Landscapes, Locales, and Artefacts, edited by Clive Gamble and Martin Porr, pp. 176-196. Routledge, New York. Stahl, Jenny

2008 Who Were the Flintknappers? A Study of Individual Characteristics. Lithic Technology 33(2), Fall: 161-172.

Stapert, Dick

2007 Neanderthal Children and Their Flints. PalArch's Journal of Archaeology of Northwest Europe 1-2:15-39. 
Sternke, Farina, and Mikkel Sorensen

2009 The Identification of Children's Flint Knapping Products in Mesolithic Scandinavia. In Mesolithic Horizons: Papers Presented at the Seventh International Conference on the Mesolithic of Europe, Belfast 2005, edited by Sinead McCartan, Rick Schulting, Graeme Warren, and Peter Woodman, pp. 722-729. Oxbow Books, Oxford.

Stout, Dietrich

2002 Skill and Cognition in Stone Tool Production: An Ethnographic Case Study from Irian Jaya. Current Anthropology 43:693-722.

Van Peer, Phillip

1992 The Levallois Reduction Strategy. Monographs in World Archaeology No. 13. Prehistory Press, Madison.

Vaquero, Manuel

2008 The History of Stones: Behavioural Inferences and Temporal Resolution of an Archaeological Assemblage from the Middle Paleolithic. Journal of Archaeological Science 35:3178-3185.

Weedman, Kathryn

2002 On the Spur of the Moment: Effects of Age and Experience on Hafted Stone Scraper Morphology. American Antiquity 67(4):731-744.

Wenban-Smith, Francis F.

1996 The Palaeolithic Archaeology of Baker's Hole: A Case-Study for Focus in Lithic Analysis. Unpublished
Ph.D. dissertation, Department of Archaeology, University of Southampton.

Whittaker, John C.

1987 Individual Variation as an Approach to Economic Organization: Projectile Points at Grasshopper Pueblo, Arizona. Journal of Field Archaeology 14:465-479.

1994 Flintknapping: Making and Understanding Stone Tools. University of Texas Press, Austin.

Wiessner, Polly

1983 Style and Social Information in Kalahari San Projectile Points. American Antiquity 48(2):253-276.

Winton, Vicky

2005 An Investigation of Knapping-Skill Development in the Manufacture of Palaeolithic Handaxes. In Stone Knapping: The Necessary Conditions for a Uniquely Hominin Behavior, edited Valentine Roux and Blandine Bril, pp. 109-116. McDonald Institute for Archaeological Research, Oxford.

Submitted September 7, 2009; Revised November 12, 2009; Accepted January 7, 2010. 